\title{
Micro Approaches to Foreign Exchange Determination
}

December 2010

\author{
Martin D. D. Evans ${ }^{1}$ \\ Georgetown University and NBER \\ Department of Economics \\ Washington DC 20057 \\ Tel: (202) 687-1570 \\ evansm1@georgetown.edu
}

\author{
Dagfinn Rime \\ Research Department \\ Norges Bank \\ Tel: 47-22 316757 \\ Dagfinn.Rime@Norges-Bank.no
}

\begin{abstract}
Keywords: Exchange Rate Dynamics, Microstructure, Order Flow.
\end{abstract}

JEL Codes: F3; F4; G1. 


\section{Introduction}

Micro-based exchange-rate research examines the determination and behavior of spot exchange rates in an environment that replicates the key features of trading in the foreign exchange (FX) market. Traditional macro exchange-rate models play little attention to how trading in the FX market actually takes place. The implicit assumption is that the details of trading are unimportant for the behavior of exchange rates over months, quarters or longer. Micro-based models, by contrast, examine how information relevant to the pricing of FX becomes reflected in the spot exchange rate via the trading process. According to this view, trading is not an ancillary market activity that can be ignored when considering exchange-rate behavior. Rather, trading is an integral part of the process through which spot rates are determined and evolve.

The past decade of micro-based research has uncovered a robust and strong empirical relation between exchange rates and measures of FX trading activity. One measure in particular, order flow (i.e., the net of buyer- and seller-initiated FX trades) appears as the proximate driver of exchangerate changes over horizons ranging from a few minutes to a few months. This finding supports the view that trading is an integral part of exchange-rate determination. It also stands in stark contrast to the well-known deficiencies of macro models in accounting for exchange-rate variations over horizons shorter than a couple of years.

In this chapter we provide an overview of micro-based research on exchange-rate determination. Originally, research was focused on partial equilibrium models - the traditional domain of microstructure research. These models provide an explanation for why order flow is a proximate driver of exchange-rate changes over short horizons. Recent micro-based research moves away from partial equilibrium models to focus on the link between currency trading and macroeconomic conditions in the general equilibrium setting of modern macroeconomic models. This research aims to provide the micro-foundations for the exchange-rate dynamics that having been missing from traditional macro models. The models provide new perspectives on the behavior of exchange rates over horizons that are relevant to researchers and policy-makers concerned with international macroeconomic issues. They also produce theoretical predictions concerning the links between exchange rates, order flow, and macroeconomic factors that are supported by the data. These findings suggest that we may finally be making some progress towards understanding the links between macroeconomic conditions and the behavior of exchange rates over macro- and policy-relevant horizons.

We structure our discussion as follows: In Section 2 we provide a broad overview of the key differences between the traditional macro view of exchange-rate determination and the micro-based approach. This discussion also provides some perspective on why the empirical performance of macro and micro-based exchange rate models is so different. Section 3 first lays out the key features of the FX market and describes how they are incorporated into a canonical partial equilibrium model of currency trading. We then discuss the empirical implications of the model and the relevant micro-based empirical literature. Section 4 examines research that links spot rate dynamics to macroeconomic conditions via currency trading. Section 5 concludes with some thoughts on the 
directions of future micro-based exchange-rate research.

\section{Perspectives on Spot Rate Dynamics}

We begin by providing a broad perspective on the possible factors that drive spot exchange rates. For this purpose, we first derive a simple decomposition for the period-by-period depreciation rate that must hold in any exchange-rate model, i.e., traditional macro models and micro-based models. We then use this decomposition to identify the key differences between micro-based models and their traditional macro counterparts.

\subsection{Decomposition of Depreciation Rates}

We begin with some definitions. Let $s_{t}$ denote the log spot exchange rate defined as the domestic price of foreign currency. The log excess return on foreign currency between periods $t$ and $t+1$ is $e r_{t+1}=s_{t+1}-s_{t}+r_{t}^{*}-r_{t}$, where $r_{t}$ and $r_{t}^{*}$ denote the home and foreign one-period nominal interest rates. We define the foreign exchange risk premium, $\delta_{t}$, as the expected log excess return, $\mathbb{E}_{t} e r_{t+1}=\delta_{t}$, where $\mathbb{E}_{t}$ denotes expectations conditioned on period- $t$ information, $\Omega_{t}$. For the present, all we shall assume is that $\Omega_{t}$ contains the period- $t$ spot rate and interest rates: $s_{t}, r_{t}$ and $r_{t}^{*}$.

Our aim is to provide a decomposition for the period-by-period depreciation rate, $\Delta s_{t+1}=$ $s_{t+1}-s_{t}$. For this purpose we first combine the definitions of $e r_{t+1}$ and $\delta_{t}$ to write

$$
\Delta s_{t+1}=r_{t}-r_{t}^{*}+\delta_{t}+\left(s_{t+1}-\mathbb{E}_{t} s_{t+1}\right)
$$

In words, the depreciation rate must be equal to the sun of the interest differential, $r_{t}-r_{t}^{*}$; the risk premium, $\delta_{t}$; and the error in forecasting the period- $t+1$ spot rate, $s_{t+1}-\mathbb{E}_{t} s_{t+1}$.

To identify the forecast error, we introduce our first economic assumption. In modern macro models short-term interest rates are viewed as the policy instruments of central banks who react to changing macroeconomic conditions in pursuit of their monetary policy goals. With this in mind, we assume that expectations about the future path of domestic and foreign interest rates incorporate a view on how central banks react to changes in the macroeconomy. In particular,

$$
\mathbb{E}_{t}\left(r_{t+i}^{*}-r_{t+i}\right)=\left(1+\gamma_{\pi}\right) \mathbb{E}_{t}\left(\Delta p_{t+1+i}^{*}-\Delta p_{t+1+i}\right)+\gamma_{y} \mathbb{E}_{t}\left(y_{t+i}^{*}-y_{t+i}\right)-\gamma_{q} \mathbb{E}_{t} q_{t+i},
$$

for $i>0$, where $\gamma_{\pi}, \gamma_{y}$ and $\gamma_{q}$ are positive coefficients.

Equation (2) says that the expected future differential between foreign and domestic rates is higher when: (i) the future difference between foreign and home inflation, $\Delta p_{t+1}^{*}-\Delta p_{t+1}$, is higher; (ii) the difference between the foreign and home output gaps, $y_{t}^{*}-y_{t}$, widens; or (iii) when the real exchange rate, $q_{t}=s_{t}+p_{t}^{*}-p_{t}$, depreciates. The first two terms are consistent with the widelyaccepted view that central banks react to higher domestic inflation and output by raising short-term 
interest rates. The third term captures the idea that some central banks can be expected to react to deviations in the spot rate from its purchasing power parity level - a notion that finds empirical support in Clarida et al. (1998).

We now identify the implications of these interest rate expectations for the behavior of the spot rate forecast error, $s_{t+1}-\mathbb{E}_{t} s_{t+1}$. By definition, $s_{t+1}=r_{t+1}^{*}-r_{t+1}-\delta_{t+1}+\mathbb{E}_{t+1} s_{t+2}$, so taking conditional expectations gives

$$
\mathbb{E}_{t} s_{t+1}=\mathbb{E}_{t}\left(r_{t+1}^{*}-r_{t+1}-\delta_{t+1}\right)+\mathbb{E}_{t} s_{t+2}
$$

Substituting for interest rate expectations with (2), and iterating forward we find that

$$
\mathbb{E}_{t} s_{t+1}=\mathbb{E}_{t} \sum_{i=1}^{\infty} \rho^{i}\left(f_{t+i}-\delta_{t+i}\right)+\mathbb{E}_{t} \lim _{i \rightarrow \infty} \rho^{i} s_{t+i}
$$

with $\rho=1 /\left(1+\gamma_{q}\right)<1$, where macro fundamentals are

$$
f_{t}=\left(1+\gamma_{\pi}\right)\left(\Delta p_{t+1}^{*}-\Delta p_{t+1}\right)+\gamma_{y}\left(y_{t}^{*}-y_{t}\right)+\gamma_{q}\left(p_{t}-p_{t}^{*}\right) .
$$

To rule out the effects of asset-pricing bubbles, we assume that $\mathbb{E}_{t} \lim _{i \rightarrow \infty} \rho^{i} s_{t+i}=0$ so that (4) becomes

$$
\mathbb{E}_{t} s_{t+1}=\frac{\rho}{1-\rho} \mathbb{E}_{t} f_{t}+\frac{1}{1-\rho} \mathbb{E}_{t} \sum_{i=1}^{\infty} \rho^{i} \Delta f_{t+i}-\mathbb{E}_{t} \sum_{i=1}^{\infty} \rho^{i} \delta_{t+i} .
$$

Equation (5) identifies the expected spot rate next period in terms of the estimate of current macro fundamentals, $\mathbb{E}_{t} f_{t} ;$ forecasts of future changes in fundamentals, $\mathbb{E}_{t} \Delta f_{t+i}$, and expectations about the future risk premia, $\mathbb{E}_{t} \delta_{t+i}$.

Finally, we combine (3) with the identity, $s_{t+1}=r_{t+1}^{*}-r_{t+1}-\delta_{t+1}+\mathbb{E}_{t+1} s_{t+2}$, to give

$$
s_{t+1}-\mathbb{E}_{t} s_{t+1}=r_{t+1}^{*}-r_{t+1}-\delta_{t+1}-\mathbb{E}_{t}\left(r_{t+1}^{*}-r_{t+1}-\delta_{t+1}\right)+\left(\mathbb{E}_{t+1}-\mathbb{E}_{t}\right) s_{t+2} .
$$

Notice that the last term on the right is equal to $\left(\mathbb{E}_{t+1}-\mathbb{E}_{t}\right) \mathbb{E}_{t+1} s_{t+2}$ by the law of iterated expectations. So, substituting for $\mathbb{E}_{t+1} s_{t+2}$ from (5) gives

$$
\begin{aligned}
s_{t+1}-\mathbb{E}_{t} s_{t+1} & =\left(1-\mathbb{E}_{t}\right)\left(r_{t+1}^{*}-r_{t+1}\right)+\frac{\rho}{1-\rho}\left(\mathbb{E}_{t+1}-\mathbb{E}_{t}\right) f_{t+1} \\
& +\frac{1}{1-\rho}\left(\mathbb{E}_{t+1}-\mathbb{E}_{t}\right) \sum_{i=2}^{\infty} \rho^{i-1} \Delta f_{t+i}-\left(\mathbb{E}_{t+1}-\mathbb{E}_{t}\right) \sum_{i=1}^{\infty} \rho^{i-1} \delta_{t+i}
\end{aligned}
$$

Since $\left\{r_{t}, r_{t}^{*}\right\} \in \Omega_{t},\left(1-\mathbb{E}_{t}\right)\left(r_{t+1}^{*}-r_{t+1}\right)=\left(1-\mathbb{E}_{t}\right) \Delta\left(r_{t+1}^{*}-r_{t+1}\right)$. We can therefore combine this 
expression with (1) to produce

$$
\begin{aligned}
\Delta s_{t+1} & =r_{t}-r_{t}^{*}-\left(1-\mathbb{E}_{t}\right) \Delta\left(r_{t+1}-r_{t+1}^{*}\right) \\
& +\frac{\rho}{1-\rho}\left(\mathbb{E}_{t+1}-\mathbb{E}_{t}\right) f_{t+1}+\frac{1}{1-\rho}\left(\mathbb{E}_{t+1}-\mathbb{E}_{t}\right) \sum_{i=2}^{\infty} \rho^{i-1} \Delta f_{t+i} \\
& +\delta_{t}-\left(\mathbb{E}_{t+1}-\mathbb{E}_{t}\right) \sum_{i=1}^{\infty} \rho^{i-1} \delta_{t+i} .
\end{aligned}
$$

Equation (6) decomposes variations in the depreciation rate into three sets of factors: policydetermined interest rates, revisions in expectations about current and future fundamentals, and the anticipated path for the risk premium. Monetary policy affects the depreciation rate via the period- $t$ differential, and via unexpected changes in the interest differential as identified by the terms in the first line on the right-hand side. The terms in the second line identify the influence of macro fundamentals. These terms only appear because expectations concerning future interest rates are correlated with forecasts of future macro fundamentals. The terms in the last row identify the role of the risk premia. The period- $t$ risk premia, $\delta_{t}$, affects the depreciation rate via its impact on $\mathbb{E}_{t} \Delta s_{t+1}$, while the present value term contributes to $s_{t+1}-\mathbb{E}_{t} s_{t+1}$. Again, we stress that this decomposition follows from just two assumptions: the assumption on interest rate forecasts in (2); and the "no bubble" assumption, $\mathbb{E}_{t} \lim _{i \rightarrow \infty} \rho^{i} s_{t+i}=0$.

\section{$2.2 \quad$ Macro and Micro Perspectives}

The decomposition of the depreciation rate in (6) allows us to clearly identify the key differences between micro-based exchange-rate models and the their traditional macro counterparts. Broadly speaking, these differences appear in two areas: (i) the specification of the conditioning information set used to compute expectations, and (ii) the specification of the risk premium, $\delta_{t}$.

Macro models of exchange-rate determination typically assume that agents (i.e., households, firms and central banks) have the same information about the structure of the economy and observe its current state. In the context of equation (6) this means that current prices, inflation, and output gaps are also part of the period- $t$ common information set, $\Omega_{t}$. Assumptions about the risk premium vary. Many traditional models assume some version of uncovered interest parity so the risk premium is zero or a constant. In contrast, modern macro models identify the risk premium from the covariance between currency returns and the macro risk factors driving the stochastic discount factor (SDF) that prices all financial assets in an economy without arbitrage opportunities. The risk premium can vary in these models, but estimates in the literature are typically close to zero. ${ }^{2}$

\footnotetext{
${ }^{2}$ At their heart, macro models for the risk premium require: (i) that any expected excess currency return that differs from zero should covary with the SDF, and (ii) that differences between expected returns are proportional to the difference in the covariance between returns and the SDF. Unfortunately, researchers have yet to find evidence satisfying the first condition for specifications of the SDF based on macro variables. For example, a comprehensive recent study by Burnside et al. (2006) finds that the excess returns from carry-trade strategies have no significant covariance with a wide array of risk factors.
} 
With these assumptions, the macro perspective on the factors driving depreciation rates focuses on the terms in the first two lines of equation (6). The first identifies the effect of current and unanticipated changes in short-term interest rates. In practice, current interest differentials (i.e., $\left.r_{t}-r_{t}^{*}\right)$ typically account for very little of the variation in depreciation rates. Furthermore, central banks change interest rates relatively rarely; and when they do, they often communicate their intentions beforehand so as not to put undue stress on the financial system. As a result, unanticipated changes in short-term interest are not an important source of spot rate changes over weeks, months and quarters. ${ }^{3}$ This leaves the terms involving macro fundamentals, $f_{t}$.

By definition, $\left(\mathbb{E}_{t+1}-\mathbb{E}_{t}\right) f_{t+1}=\left(\mathbb{E}_{t+1}-\mathbb{E}_{t}\right)\left(f_{t+1}-f_{t-1}\right)+\left(\mathbb{E}_{t+1}-\mathbb{E}_{t}\right) f_{t-1}$. So if the current state of the macroeconomy is common knowledge as macro models assume, $\left(\mathbb{E}_{t+1}-\mathbb{E}_{t}\right) f_{t-1}=0$, and equation (6) becomes ${ }^{4}$

$$
\Delta s_{t+1} \cong \frac{\rho}{1-\rho}\left(\mathbb{E}_{t+1}-\mathbb{E}_{t}\right)\left(f_{t+1}-f_{t-1}\right)+\frac{1}{1-\rho}\left(\mathbb{E}_{t+1}-\mathbb{E}_{t}\right) \sum_{i=2}^{\infty} \rho^{i-1} \Delta f_{t+i} .
$$

Suppose one period spans a month or quarter. Under normal circumstances, the first term on the right should be close to zero because macro fundamentals are unlikely to change significantly over this time span. Thus, from a macro perspective, the lion's share of the link between macro fundamentals and monthly/quarterly variations in spot rates must be attributable to the second term on the right-hand-side of (7): i.e., the revisions in forecasts about future changes in fundamentals, $\Delta f_{t+i}$ for $i>1$. However, the time series properties of the macro variables used to construct fundamentals, $\hat{f}_{t}$, in the macro exchange-rate literature imply very little variation in the estimates of the present value of future changes in $\hat{f}_{t}$. As a result, estimates of the second term in (7) using $\hat{f}_{t}$ account for at most $5 \%$ of the variance of the depreciation rates at the monthly and quarterly horizons. ${ }^{5}$ This lack of empirical success has given credence to the view that exchange rates are largely disconnected from macro fundamentals; a view Obstfeld and Rogoff (2001) call the exchange-rate disconnect puzzle.

Micro-based models bring a different perspective on spot-rate dynamics for two reasons. First, they consider much richer informational environments where agents have different and incomplete information about market and macro conditions. As a result, the information conditioning expectations in (6) no longer represents common public information. Second, micro-based models produce significant variations in the risk premium that are unrelated to the risk factors found in macro models. Consequently, micro-based models can account for variations in spot rates in the absence of changes in interest rates and/or fundamentals.

A key feature of micro-based models is that they treat the spot exchange rate as the price of

\footnotetext{
${ }^{3}$ This is not to say that unexpected changes in monetary policy have no exchange rate effects. For example, Faust et al. (2007) found that unexpected changes in the Fed Funds rate accounted for $20 \%$ of the variance in the USD/DEM(EUR) depreciation rate in the 20 minutes following the change. The point is simply that such events account for very small fraction of the total variation in spot rates over weeks, months, and longer.

${ }^{4}$ Notice that we focus here only on the terms involving macro fundamentals, or equivalently on circumstances where $r_{t}=r_{t}^{*}$ and $\delta_{t}=0$.

${ }^{5}$ See, for example, Engel and West (2006) and Mark (2009). Chapter 3 in Evans (2011) contains a detailed discussion of this point.
} 
FX that dealers quote to each other and agents outside the market as part of the trading process. Thus the dynamics of spot exchange rates literally reflects the changes in dealers' FX quotes. This dealer-centered perspective has two critical implications for exchange-rate determination. First, at any point in time the spot exchange rate can only reflect information known to the dealers making quotes. In terms of equation (6), expectations are conditioned on the period $-t$ common information available to all dealers. Second, information known to dealers will only be embedded in the spot exchange rate if they find it optimal from a trading perspective to base their quotes on that information; i.e., the information is price-relevant. These implications are straightforward, but open up new conceptual space for thinking about exchange-rate dynamics.

To illustrate this point, consider the terms involving fundamentals from equation (6) where we replace $\mathbb{E}_{t+1}$ by $\mathbb{E}_{t+1}^{\mathrm{D}}$ to emphasize that the expectations are conditioned on dealers' information:

$$
\frac{\rho}{1-\rho}\left(\mathbb{E}_{t+1}^{\mathrm{D}}-\mathbb{E}_{t}^{\mathrm{D}}\right) f_{t+1}+\frac{1}{1-\rho}\left(\mathbb{E}_{t+1}^{\mathrm{D}}-\mathbb{E}_{t}^{\mathrm{D}}\right) \sum_{i=2}^{\infty} \rho^{i-1} \Delta f_{t+i}
$$

Micro-based models do not assume that dealers have contemporaneous information on all the macro variables that comprise fundamentals. In accordance with reality, information on macroeconomic conditions only becomes available via the release of macro data with reporting lags of up to several months. Thus, the first term in (8) can contribute to short-term variations in spot rates as dealers learn about the current (i.e., period-t) macroeconomic conditions that comprise fundamentals. As we shall see, this turns out to be empirically important: Some of the high frequency behavior of spot rates reflects the flow of new information reaching dealers concerning the slowly evolving state of the macroeconomy.

Variations in the risk premium also play an important role in micro-based models. When dealers determine their FX quotes they include a risk premium, $\delta_{t}$, that compensates them for the risks of being a marketmaker. These risks arise because the dealer stands ready to fill the currency orders of other market participants, and can vary significantly as market conditions change. They are also quite different from the risks faced by other market participants, such as investors, identified in macro models. As a consequence, the terms involving the risk premia from equation (6):

$$
\delta_{t}-\left(\mathbb{E}_{t+1}^{\mathrm{D}}-\mathbb{E}_{t}^{\mathrm{D}}\right) \sum_{i=1}^{\infty} \rho^{i-1} \delta_{t+i},
$$

play a significant role in the determination of depreciation rates in micro-based models. We discuss this role of the risk premium in Sections 3 and 4 below.

Micro-based models also differ from their traditional counterparts in terms of the information sources driving dealers' expectations. As in macro models, dealers can change their expectations in response to public data releases that contain information on past economic conditions. They can also revise their expectations in response to contemporaneously observed macroeconomic shocks, such as natural disasters; or other public news. More uniquely to micro-models, dealers also receive information from their observations on the patterns of currency trading. This source of information 
is ignored by macro models, but it turns out to by very important empirically. In particular, one measure of trading activity, order flow, accounts for as much as $60 \%$ to $70 \%$ of the variations in spot rates at a daily frequency.

Foreign currency order flow is defined as the difference between the value of purchase and sale orders for FX initiated by traders against dealers spot rate quotes during a specified trading period. A key element in this definition is the initiator of trade. In every trade there is a buyer and seller of FX, but only one party to the trade initiates the transaction. The initiator is the one paying transaction costs, and presumably so for a reason. Hence, by tracking who initiates each trade, order flow provides a measure of the information exchanged between counterparties in a series of FX transactions. In micro-based models this information may concern fundamentals and/or the determinants of the risk premium. In the former case, order flow is a proximate driver of the depreciation rate via the terms in (8). When order flow conveys information about the risk premium, it is a proximate driver of depreciation rates via the terms in (9). We will discuss why order flow plays this role below.

In summary, micro-based models bring a new perspective to understanding the sources of spotrate variations because they focus on the flow of information reaching dealers and the compensation they require to act as marketmakers in currency markets. In the sections that follow we examine the theoretical foundations of these features and discuss the supporting empirical evidence.

\section{Currency Trading Models and their Implications}

One goal of micro-based research is to build exchange-rate models from microeconomic foundations that reasonably represent the key features of the FX market. In particular, the aim is to incorporate the institutional implications of how information is transmitted from one agent to another as trading takes place, and to study how this information flow is ultimately reflected in the spot exchange rate.

No model can incorporate all the institutional features of trading in the FX market - its far too complex. Instead, micro-based models focus on a small number of features that are viewed as essential for understanding the main economic mechanisms at work. The structure of the FX market is discussed in more detail in the chapter by King et al. We summaries the key features below.

FX dealers working in banks are the key intermediaries in the FX market. The FX market is a two-tier market in the sense that the end-users of currency trade with dealers in the retail market, and dealers trade with other dealers in the interbank market. End-users only very rarely trade with each other. Neither the interbank nor the retail market has a physical location. Trades are made by phone or electronically between participants located all around the world, and trading can take place continuously 24 hours a day. However, a majority of the trading in the interbank market involve banks in a few financial centers (Tokyo, Singapore, Frankfurt, New York, and particularly London), and activity is heavily concentrated during the daytime hours of these main financial centers.

In the interbank market FX dealers trade both directly and indirectly with each other. Direct interdealer trading, typically bilateral "conversations" between two dealers over a computer network 
called Reuters D2000-1, was the dominant form of interbank trading before the mid 1990s. Since then, more and more interbank trades are matched indirectly via the market and limit orders to buy and sell currencies that dealers submit to two electronic brokers, Reuters D2000-2 and EBS.

The lack of a physical location and the structure and number of trading systems implies that no FX dealer has complete information about the state of the interbank market. Direct interdealer trading takes place simultaneously across the interbank market, and dealers only have information on the direct trades they participate in. Electronic brokerages provide market-wide information on transaction prices, and thereby give dealers signals on the market-wide order flow, but the dealers do not observe the structure of limit orders that determine market liquidity. And since there are no regulatory bodies requiring disclosure of trades, the dealers do not know who is behind the trades observed on the electronic brokers.

The FX orders from end-users (often called customer orders) received by banks represent the most important source of private information to FX dealers. Dealers working at banks with a large customer base and a world-wide reporting system have a potentially important informational advantage over other market participants. Customer orders come from many different end-user types and may be generated by allocative, speculative and risk-management factors. Customer orders that are purely a function of current and past currency prices are termed feedback orders. FX dealers face constraints on both the duration and size of their FX positions. Their overnight positions are typically small or zero.

\subsection{The Portfolio Shifts Model}

The Portfolio Shifts (PS) model developed by Lyons (1997) and Evans and Lyons (2002a) incorporates many of these features into a model that examines how trading in the interbank and retail tiers of the FX market relates to the evolution of the spot exchange rate. The model describes trading in a single currency pair among a large number of dealers, a broker and between dealers and investors over a stylized trading day. Here we extend the model to allow for the effects of data releases.

\subsubsection{Overview}

There is one risky asset representing FX and one risk-free asset with a daily return of $1+r$. The economy is populated by a continuum of risk-averse investors indexed by $n \in[0,1]$ and D risk-averse dealers indexed by $d$. Each day $t$, is split into three trading rounds; I, II and III. The sequence of events throughout day $t$ is shown in Figure 1.

At the start of round I on day $t$, all investors, dealers and the broker observe the dividend paid to the current holders of FX. The value of the dividend, $D_{t}$, is assumed to follow a random walk

$$
D_{t}=D_{t-1}+V_{t},
$$




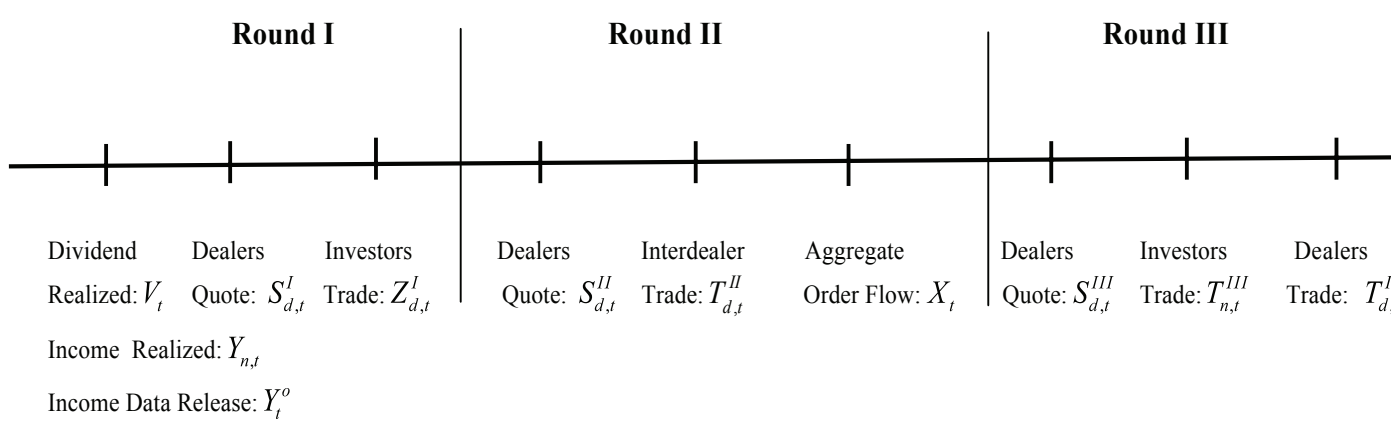

Figure 1: Daily Timing in the Portfolio Shifts Mode

where $V_{t} \sim i . i . d . N\left(0, \sigma_{v}^{2}\right)$. Realizations of $V_{t}$ represent the arrival of public macro information over time (e.g., changes in interest rates). At the start of the day each investor $n$ also receives FX income,

$$
Y_{n, t}=Y_{t}+\xi_{n, t}
$$

where $Y_{t}$ and $\xi_{n, t}$ are i.i.d. mean-zero normal random variables that represent the aggregate and idiosyncratic components of income. $Y_{n, t}$ is private information to each investor and generates a hedging motive for the customer orders in round-I trading. Investors do not initially observe either component, but in equilibrium they learn the value of $Y_{t}$ by the end of day $t$.

Data releases take place on a pre-specified schedule. At the start of round I on a release day everyone also observes an estimate of aggregate foreign income, $Y_{t}^{o}$. This estimate is related to actual foreign income by

$$
Y_{t}^{o}=Y_{t}+U_{t}
$$

where $U_{t} \sim$ i.i.d.N $\left(0, \sigma_{\mathrm{U}}^{2}\right)$.

The retail tier of the market opens in round I. Each dealer simultaneously and independently quotes a scalar price at which they will fill customer orders to buy or sell FX. The round-I price quoted by dealer $d$ is denoted by $S_{d, t}^{\mathrm{I}}$. Prices are publicly observed by all dealers and investors and are good for orders of any size. Investors then place their orders for FX. Orders may be placed with more than one dealer. If two or more dealers quote the same price, the customer order is randomly assigned among them. ${ }^{6}$ The customer orders received by dealer $d$ are denoted by $Z_{d, t}^{\mathrm{I}}$. Positive (negative) values of $Z_{d, t}^{\mathrm{I}}$ denote net customer purchases (sales) of FX. As in the actual retail market, customer orders, $Z_{d, t}^{\mathrm{I}}$, are only observed by dealer $d$.

Trading in the interbank tier of the market takes place in round II. The broker and each dealer simultaneously and independently quotes a scalar price for FX, $S_{\mathrm{B}, t}^{\mathrm{II}}$ and $\left\{S_{d, t}^{\mathrm{II}}\right\}_{d=1}^{\mathrm{D}}$. The quoted prices are observed by all dealers and are good for inter-dealer trades of any size. Each dealer then simultaneously and independently trades on other dealers' and the broker's quotes. We denote the

\footnotetext{
${ }^{6}$ The random assignment of customer trades is necessary to stop dealers from making precise inferences about $Y_{t}$ from their round-I trades with customers in equilibrium.
} 
FX orders made by dealer $d$ as $T_{d, t}^{\mathrm{II}}$ and orders received by dealer $d$ as $Z_{d, t}^{\mathrm{II}}$. Orders received by the broker are denoted by $Z_{\mathrm{B}, t}^{\mathrm{II}}$. When dealer $d$ initiates a purchases (sale) of $\mathrm{FX}, T_{d, t}^{\mathrm{II}}$ is positive (negative). Positive values of $Z_{d, t}^{\mathrm{II}}$ or $Z_{\mathrm{B}, t}^{\mathrm{II}}$ denote purchases of FX initiated by another dealer. Once again, trading with multiple dealers and the broker is feasible. If multiple agents quote the same price, trades are allocated equally between them. ${ }^{7}$ At the close of round II trading, all dealers and the broker observe aggregate interdealer order flow:

$$
X_{t}=\sum_{d=1}^{\mathrm{D}} T_{d, t}^{\mathrm{II}}
$$

Interdealer order flow, $X_{t}$, simply aggregates the purchases of FX made by dealers initiating trades against other dealers' quotes and the broker's quote.

The retail tier of the market re-opens in round III. The broker and dealers again simultaneously and independently quote prices, $S_{\mathrm{B}, t}^{\mathrm{III}}$ and $\left\{S_{d, t}^{\mathrm{III}}\right\}_{d=1}^{\mathrm{D}}$, at which they will fill dealer and customer orders, respectively. Investors observe all the prices and then place their orders with dealers. As above, orders may be placed with more than one dealer and are randomly assigned to dealers quoting the same prices. The round III customer orders received by dealer $d$ are denoted by $Z_{d, t}^{\mathrm{III}}$. Once each dealer has filled his customer orders, he can trade with the broker. ${ }^{8}$

Clearly, this sequence of events represents a simplified view of trading in the actual FX market. It does, however, allow us to analyze how information pertinent to the spot exchange rate is learnt by dealers via trading. In particular, the focus of the model is on how information about the aggregate demand for FX contained in the customer orders at the start of the day becomes learnt by dealers and reflected in the FX prices they quote at the end of day. As we shall see, this information aggregation process produces an important empirical prediction linking trading activity to exchange-rate dynamics.

\subsubsection{Equilibrium}

The model's equilibrium comprises: (i) a set of optimal FX orders by investors in rounds I and III; (ii) a set of optimal FX price quotes by dealers in rounds I - III, and the broker in rounds II and III; and (iii) a set of optimal dealer trading decisions in rounds II and III, such that markets clear (i.e., there is a counterparty for every trade in each round).

\footnotetext{
${ }^{7}$ Unlike round I, there is no random assignment of trades between dealers quoting the same price in round II. This assumption makes the single round of interdealer trading more transparent than customer-dealer trading in round $\mathrm{I}$. Alternatively, we could generate greater transparency in interdealer trading by including multiple rounds of interdealer trading with random assignment, but such a formulation of the model would be much less tractable.

${ }^{8}$ It is tempting to think that the broker plays no real role in the model because he simply quotes the same price as dealers in rounds II and III, but this is not the case. In round III, the presence of the broker allows each dealer to hold no FX inventory overnight, consistent with the efficient risk-sharing allocation, even though each dealer is left with different holdings after filling customer orders. In round II, the broker absorbs the imbalance of trades among dealers so that in aggregate they can achieve their desired FX holdings. For a further discussion of the broker's role, see Chapter 6 in Evans (2011).
} 
Days without Macro Data Releases When all market participants act to maximize expected utility defined over future wealth, the equilibrium of the model is summarized by:

1. All dealers quote the same price for FX in each round of trading, i.e. $S_{d, t}^{i}=S_{t}^{i}$ for $i=\{\mathrm{I}$, II, III $\}$. The broker quotes the same price as dealers in rounds II and III. Common quotes are given by

$$
\begin{aligned}
S_{t}^{\mathrm{I}} & =S_{t-1}^{\mathrm{III}}-\lambda_{\mathrm{A}} A_{t-1}+\frac{1}{r} V_{t}, \\
S_{t}^{\mathrm{II}} & =S_{t}^{\mathrm{I}}, \quad \text { and } \\
S_{t}^{\mathrm{III}} & =S_{t}^{\mathrm{II}}+\lambda_{\mathrm{A}} A_{t-1}+\lambda_{\mathrm{X}}\left(X_{t}-\mathbb{E}\left[X_{t} \mid \Omega_{t}^{\mathrm{II}}\right]\right), \quad \lambda_{\mathrm{x}}>0,
\end{aligned}
$$

where $A_{t-1}$ denotes investors' aggregate holding of FX at the end of day $t-1$, and $\Omega_{t}^{\text {II denotes }}$ common information of dealers and the broker at the start of round II.

2. The trades initiated by dealer $d$ in round II are

$$
T_{d, t}^{\mathrm{II}}=\alpha_{\mathrm{Z}} Z_{d, t}^{\mathrm{I}}+\alpha_{\mathrm{A}} A_{t-1},
$$

and the customer orders received by dealer $d$ are in round I are

$$
Z_{d, t}^{\mathrm{I}}=(\beta / \mathrm{D}) Y_{t}+\varepsilon_{d, t}, \quad \beta<0,
$$

where $\sum_{d=1}^{\mathrm{D}} \varepsilon_{d, t}=0$.

There are several noteworthy features of this equilibrium. First, consider its implications for the behavior of the spot exchange rate at the daily frequency:

$$
S_{t}^{\mathrm{III}}-S_{t-1}^{\mathrm{III}}=\frac{1}{r} V_{t}+\lambda_{\mathrm{X}}\left(X_{t}-\mathbb{E}\left[X_{t} \mid \Omega_{t}^{\mathrm{II}}\right]\right)
$$

Daily changes in the spot exchange rate are driven by shocks to dividends and unexpected interdealer order flow. The former reflect the effects of public news while the latter conveys information that was initially dispersed across investors and was then aggregated via trading in the FX market.

Dividend shocks play a familiar role in the determination of the spot rate. Realizations of $V_{t}$ are public information, and affect the forecasts of future dividends by all dealers and investors in exactly the same way. Consequently, it should come as no surprise that $V_{t}$ shocks are immediately reflected in the equilibrium spot rate. That said, it is important to remember that quotes are chosen optimally in this model, so $V_{t}$ shocks only affect the spot rate because dealers have an incentive to adjust their quotes once the value of $V_{t}$ is known (see equation 14a).

The role played by aggregate interdealer order flow in (17) is more complex. Notice that it is unexpected interdealer order flow that affects the exchange rate in (17). The reason is that dealers adjust their quotes between rounds II and III to account for the new information contained 
in aggregate interdealer order flow (see equation 14c). The customer orders received by each dealer reflect the difference between the desired and actual FX positions of individual investors. As such, they convey information to dealers about both the current income and the overnight positions of a subset of investors. This information is effectively shared between dealers via interdealer trading in round II. As a result, $X_{t}$ conveys information about aggregate income and the prior overnight $\mathrm{FX}$ position of all investors. Since the latter is already known to dealers, $X_{t}-\mathbb{E}\left[X_{t} \mid \Omega_{t}^{\amalg I}\right]$ is proportional to the new information concerning income that is incorporated into the round III quote, $S_{t}^{\text {III }}$.

Of course, the mere fact that unexpected interdealer order flow conveys new information about aggregate income to dealers does not explain why $X_{t}-\mathbb{E}\left[X_{t} \mid \Omega_{t}^{\text {II }}\right]$ appears in equation (17). For that we need to understand why dealers find it optimal to incorporate the new income information they learn into their common round III quote. In short, why is information on aggregate income, $Y_{t}$, relevant for the pricing of FX? The answer is quite simple. As in the actual market, dealers do not want to hold FX overnight - the risk of holding FX can be shared more efficiently by investors than by individual dealers. Consequently, each dealer's aim in round-III is to quote a price that will induce investors to purchases all the FX currently held by dealers. In other words, the round III quote is chosen so that the excess overnight return expected by investors is such that they want to hold the entire existing stock of FX. Obviously, this would not be possible unless all dealers can calculate what the existing stock of FX is. However, since investors' income is the only source of FX, the existing stock can be computed from the history of aggregate income. Thus, information on $Y_{t}$ is price-relevant because it reveals to dealers what aggregate overnight FX position investors must be induced to hold. In sum, interdealer order flow conveys information about the shift in the FX portfolios of investors needed to achieve efficient risk-sharing. This is the origin of the term, Portfolio Shifts.

Another important feature of the model concerns timing. As we noted above, public news concerning current and future dividends is immediately and fully incorporated into the spot exchange rate. By contrast, it takes time for the information concerning income to be reflected in the dealer quotes. The reason for the delay is important. Information about income is originally transmitted to dealers via the customer orders they receive in round I (see equation 16). Thus, each dealer has some information about $Y_{t}$ at the start of round II, but the information is imprecise. At this point, each dealer could choose to use their private information on $Y_{t}$ in setting their quote, but this is not optimal in the model's trading environment. Instead, their best strategy is to quote the same price as in round I (which is the same across all dealers and only a function of common round I information), because to do otherwise would expose the dealer to arbitrage trading losses. As a result, the equilibrium spot rate remains unchanged between rounds I and II even though dealers have information about aggregate income. The spot rate only incorporates this information when it becomes common knowledge among dealers. This process of information aggregation takes place via interdealer trading in round II. The best strategy of each dealer is to use their private information concerning income in determining the trade they wish to initiate with other dealers (see equation 15). It is for this reason that interdealer order flow provides information on aggregate income that 
becomes common knowledge to dealers by the start of round III.

Days with Macro Data Releases On days with data releases (i.e., on days when everyone observes an estimate of aggregate foreign income, $\left.Y_{t}^{o}\right)$, the equilibrium of the model is summarized by:

1. All dealers quote the same price for FX in each round of trading, and the broker quotes the same price as dealers in rounds II and III. Common quotes are given by

$$
\begin{aligned}
S_{t}^{\mathrm{II}} & =S_{t-1}^{\mathrm{III}}-\lambda_{\mathrm{A}} A_{t-1}+\frac{1}{r} V_{t}-\lambda_{\mathrm{I}} Y_{t}^{o}, \quad \lambda_{\mathrm{I}}>0, \\
S_{t}^{\mathrm{II}} & =S_{t}^{\mathrm{I}}, \quad \text { and } \\
S_{t}^{\mathrm{III}} & =S_{t}^{\mathrm{II}}+\lambda_{\mathrm{A}} A_{t-1}+\lambda_{\mathrm{III}} Y_{t}^{o}+\lambda_{\mathrm{X}}^{o}\left(X_{t}-\mathbb{E}\left[X_{t} \mid \Omega_{t}^{\mathrm{II}}\right]\right), \quad \lambda_{\mathrm{III}}>0, \lambda_{\mathrm{X}}^{o}>0 .
\end{aligned}
$$

2. The trades initiated by dealer $d$ in round II are

$$
T_{d, t}^{\mathrm{II}}=\alpha_{\mathrm{Z}} Z_{d, t}^{\mathrm{I}}+\alpha_{\mathrm{A}} A_{t-1}+\alpha_{\mathrm{Y}} Y_{t}^{o} \quad \alpha_{\mathrm{Y}}>0,
$$

and the customer orders received by dealer $d$ are in round I are

$$
Z_{d, t}^{\mathrm{I}}=(\beta / \mathrm{D})\left(Y_{t}-\kappa_{\mathrm{D}} Y_{t}^{o}\right)+\varepsilon_{d, t}, \quad \beta<0,
$$

where $\mathbb{E}\left[Y_{t} \mid \Omega_{t}^{\mathrm{I}}\right]=\kappa_{\mathrm{D}} Y_{t}^{o}$ and $\Omega_{t}^{\mathrm{I}}$ denotes common information of dealers and the broker at the start of round $\mathrm{I}$.

The trade and exchange rate dynamics described above differ in several important respects from those on non-release days. First, equations (18a) and (18c) show that data releases directly affect the spot rate quotes dealers make in rounds I and III. Second, data releases affect the pattern of trading in rounds I and II. In round I, the effects show up in the FX orders received by each dealer. In round II, they affect the size of the trade dealers initiate with each other. Data releases also affect the price-impact of interdealer order flow at the start of round III, as measured by the size of the $\lambda_{\mathrm{x}}^{o}$ coefficient in (18c).

The intuition behind these results is straightforward. Recall that dealers choose $S_{t}^{\text {III }}$ using information on foreign income, $Y_{t}$, to achieve an efficient risk-sharing FX allocation at the end of each trading day. Dealers adjust $S_{t}^{\mathrm{I}}$ in response to the release of $Y_{t}^{o}$ because it provides them with incremental information that is useful in forecasting $S_{t}^{\text {III }}$. They also adjust $S_{t}^{\mathrm{I}}$ to manage risk. In particular dealers recognize that the FX orders they receive in round I depend on the difference between investors' desired FX holdings and their existing holdings. They therefore adjust their quotes so as to offset the expected hedging effect of foreign income on investors FX orders. These actions have several important consequences. First, as (18a) shows, the spot rate immediately appreciates in response to a positive income release. Second, the change in quotes between rounds I and III 
contains a risk premium based on the data release:

$$
S_{t}^{\mathrm{III}}-S_{t}^{\mathrm{I}}=\lambda_{\mathrm{A}} A_{t-1}+\lambda_{\mathrm{III}} Y_{t}^{o}+\lambda_{\mathrm{x}}^{o}\left(X_{t}-\mathbb{E}\left[X_{t} \mid \Omega_{t}^{\mathrm{II}}\right]\right)
$$

The first term on the right-hand-side is the risk premium dealers embed in their round I quotes on non-release days, the second shows the incremental premium induced by the release. When dealers observe a positive value for $Y_{t}^{o}$ they anticipate that investors' aggregate hedging demand for FX will be lower, so they embed a larger risk premium into their round I quotes to make holding FX more attractive to investors. Thus, in contrast with standard macro models, some of the exchange-rate effects of the data release are delayed beyond the release time because dealers have a risk-sharing incentive to adjust the risk premium embedded in their spot rate quotes. Of course, this only happens here because the information contained in the data release is price-relevant but imprecise. If everyone knew that $Y_{t}^{o}=Y_{t}$, dealers would have all the information they needed to quote the efficient risk- sharing spot rate in round I, so that $S_{t}^{\mathrm{I}}=S_{t}^{\mathrm{III}}$.

Risk-sharing also affects the behavior of order flows. Equation (20) implies that both individual and aggregate customer flows should not be correlated with data releases. The reason is that dealers have a strong risk-sharing incentive to adjust their spot rate quotes immediately after the release to a level that makes customer order flows unforecastable. The idea that a data release containing bad news for the dollar should trigger positive customer order flow (i.e., customer orders to purchase FX) is simply inconsistent with dealers adjusting their quotes immediately following a data release in an efficient risk-sharing manner. Data releases have a different impact on interdealer flows. As equation (19) shows, the round II trades initiated by each dealer depend on $Y_{t}^{o}$, and so could be forecast from public information available at the end of round I. This arises because dealers try to take advantage of the predictable change in spot rates between rounds II and III, $S_{t}^{\text {III }}-S_{t}^{\text {II }}$ (which equals $S_{t}^{\mathrm{III}}-S_{t}^{\mathrm{I}}$ because $S_{t}^{\mathrm{II}}=S_{t}^{\mathrm{I}}$ ). In short, interdealer order flows are forecastable because dealers have an risk-sharing incentive to make customer order flows unforecastable.

Data releases also affect the price-impact of order flow as measured by the $\lambda_{\mathrm{x}}^{o}$ coefficient in (18c). Intuitively, on non-release days, unexpected order flow represents the first source of information on income all dealers receive, but on release days it is the second source. An unexpected order flow of a given size therefore conveys more new information to dealers on release than non-release days, so they adjust their round III quotes by a larger amount. Notice, also, that order flows on release days provide dealers with more precise information on foreign income than was present in the data release. Investors have an incentive to trade after they observe the data release because their own foreign income provides them with more precise forecasts of future FX returns than dealers. So it is through their trades that dealers finally learn the full price-relevance of the data release.

In sum, the discussion above makes clear that the predictions of a micro-based model concerning the exchange-rate effects of data releases differs from the traditional macro view. When a data release contains imprecise but price-relevant information, dealers adjust their spot rate quotes to accommodate the new information on payoffs and the risk of providing liquidity to the market. 
This can produce predictable components in both order flows and spot rate returns following data releases. Data releases also affect the transmission of information to dealers via order flow because they alter trading patterns across the market.

\subsection{Empirical Implications}

Order flows and FX Returns The empirical implications of the PS model were first investigated by Evans and Lyons (2002a). They considered regressions of the daily depreciation rate on interdealer order flow and the change in the nominal interest differential:

$$
\Delta s_{t}=\beta_{1} X_{t}+\beta_{2} \Delta\left(r_{t}-r_{t}^{*}\right)+\zeta_{t}
$$

These regressions are motivated by (17) with $\Delta s_{t}=s_{t}-s_{t-1}$ replacing $S_{t}^{\text {III }}-S_{t-1}^{\text {III }}$, and actual interdealer order flow, $X_{t}$, replacing $X_{t}-\mathbb{E}\left[X_{t} \mid \Omega_{t}^{\mathrm{II}}\right]$. The first of these substitutions makes the empirical specification comparable to standard macro models but has no significant effect on the estimation results; the second is motivated by the assumption that expected interdealer order flow is zero. ${ }^{9}$ The nominal interest differential is included to account for the arrival of public news.

Table 1 reproduces regression results from Evans and Lyons (2002a) for the DM/USD and JPY/USD spot rates between May 1 to August 31, 1996. Their data on interdealer order flow comes from the Reuters Dealing 2000-1 system. This was the dominant platform for interdealer trading at the time, accounting for approximately $90 \%$ of all direct dealer-to-dealer trades. The table reports the coefficient estimates and standard errors in parenthesis for five versions of equation (22).

Three features of the estimation results are particularly noteworthy:

1. The coefficient on order flow, $X_{t}$, is correctly signed and significant, with $t$-statistics above 5 in versions I, II and IV of the equation for both the DM/USD and JPY/USD. The positive sign indicates that net dollar purchases - a positive $X_{t}$ - lead to a higher FX price for the Dollar. For perspective, the estimated value of 2.1 for the order flow coefficient in the DM/USD equation translates to $\$ 1$ billion of net purchases increasing the deutschemark price of a dollar by 0.8 pfennigs.

2. Almost all the explanatory power in the regressions is due to order flow. In specifications III and $\mathrm{V}$ where order flow is omitted, the $R^{2}$ statistics are less than $1 \%$ in both the DM/USD and JPY/USD equations. Moreover, the explanatory power of order flow is extraordinarily high.

\footnotetext{
${ }^{9}$ Evans and Lyons do not have information on the size of each transaction and so cannot measure true interdealer order flow (i.e., the difference in value between buyer-initiated and seller-initiated trades). However, since there is much less variation in the size of trades than in their direction, their measure for $X_{t}$ closely approximates true order flow across the market.
} 


\begin{tabular}{|c|c|c|c|c|c|}
\hline & & & Regressors & & \\
\hline & & $X_{t}$ & $\Delta\left(r_{t}-r_{t}^{*}\right)$ & $r_{t-1}-r_{t-1}^{*}$ & $R^{2}$ \\
\hline \multirow[t]{5}{*}{$\overline{\mathrm{DM} / \mathrm{USD}}$} & $\mathrm{I}$ & $\begin{array}{l}2 \cdot 14^{* *} \\
(0 \cdot 29)\end{array}$ & $\begin{array}{c}0.51 \\
(0 \cdot 26)\end{array}$ & & $0 \cdot 64$ \\
\hline & II & $\begin{array}{l}2 \cdot 15^{* *} \\
(0 \cdot 29)\end{array}$ & & & $0 \cdot 63$ \\
\hline & III & & $\begin{array}{c}0 \cdot 62 \\
(0 \cdot 77)\end{array}$ & & $0 \cdot 01$ \\
\hline & IV & $\begin{array}{l}2 \cdot 15^{* *} \\
(0 \cdot 29)\end{array}$ & & $\begin{array}{c}0 \cdot 02^{*} \\
(0 \cdot 01)\end{array}$ & $0 \cdot 64$ \\
\hline & V & & & $\begin{array}{c}0 \cdot 02 \\
(0 \cdot 02)\end{array}$ & $0 \cdot 00$ \\
\hline \multirow[t]{5}{*}{ JPY/USD } & I & $\begin{array}{l}2 \cdot 86^{* *} \\
(0 \cdot 36)\end{array}$ & $\begin{array}{l}2 \cdot 47^{* *} \\
(0.92)\end{array}$ & & $0 \cdot 46$ \\
\hline & II & $\begin{array}{l}2 \cdot 61^{* *} \\
(0 \cdot 36)\end{array}$ & & & $0 \cdot 40$ \\
\hline & III & & $\begin{array}{c}0.57 \\
(1 \cdot 20)\end{array}$ & & $0 \cdot 00$ \\
\hline & IV & $\begin{array}{l}2 \cdot 78^{* *} \\
(0 \cdot 38)\end{array}$ & & $\begin{array}{c}0.02^{*} \\
(0 \cdot 01)\end{array}$ & $0 \cdot 42$ \\
\hline & V & & & $\begin{array}{c}0 \cdot 01 \\
(0 \cdot 01)\end{array}$ & $0 \cdot 00$ \\
\hline
\end{tabular}

Notes: The table reports slope coefficients and standard errors. Statistical significance at the $5 \%$ and $1 \%$ level is denoted by $*$ and $* *$. Source: Evans and Lyons (2002a).

The $R^{2}$ statistics of $64 \%$ and $45 \%$ for the DM/USD and JPY/USD equations that include order flow are an order of magnitude higher than those found in other exchange-rate models.

3. The coefficient on the change in the interest differential is correctly signed, but is only significant in the JPY/USD equation. The positive sign arises in the sticky-price monetary model, for example, because an increase in the US interest rate requires an immediate dollar appreciation (i.e., an increase in JPY/USD) to make room for UIP-induced expected dollar depreciation.

Figure 2 provides further perspective on the results in Table 1. Here the solid plots shows the path of the spot exchange rate over the 4 month sample. The dashed plot shows cumulative order flow over the same period measured against the right hand axis. Cumulative order flow is simply the sum of daily order flow, i.e., $X_{t}^{\infty}=\sum_{i=1}^{t} X_{i}$. If all variations in spot rates reflected quote revisions driven only by order flow, the daily change in the spot rate should be proportional to daily order flow; i.e., $S_{t}-S_{t-1}=\lambda_{\mathrm{x}} X_{t}$. Under these circumstances, $S_{t}=\lambda_{\mathrm{x}} X_{t}^{\infty}$ so the plots should coincide. Figure 2 shows that this in not quite the case. Nevertheless, it is hard not to be impressed by the close correspondence between exchange rates and order flow over this sample period.

Figure 2 highlights two further features of the relation between order flow and currency returns. 


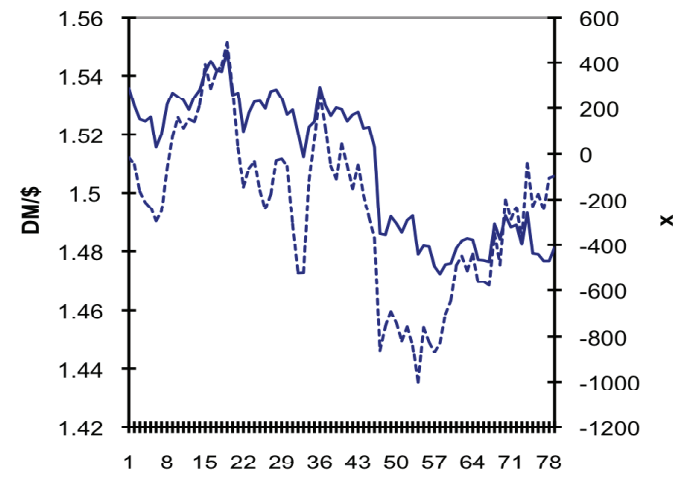

$\mathrm{DM} / \mathrm{USD}$

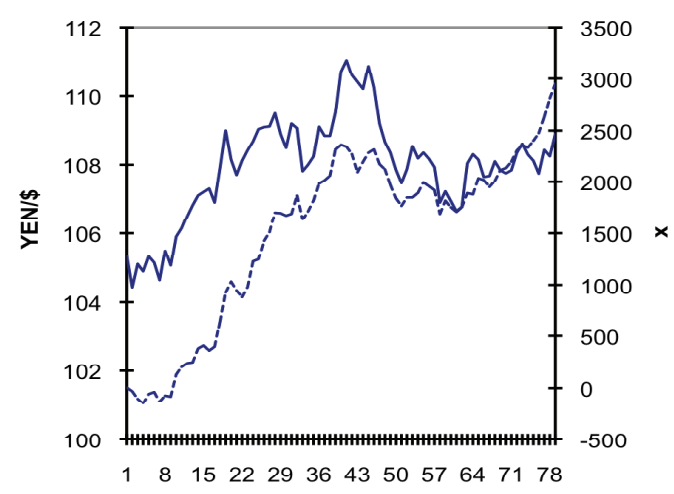

JPY/USD

Figure 2: Exchange Rates (solid) and Cumulative Order Flow (dashed). Source: Evans and Lyons (2002)

First, although the equation in (22) is estimated at the daily frequency, the estimation results have implications for the behavior of spot rates over much longer periods. In particular, since there is almost no serial correlation in daily depreciation rates, the $k$-day change in the log spot rate is well-approximated by

$$
s_{t}-s_{t-k} \cong \beta_{1} X_{t}^{k}+\beta_{2} \Delta^{k}\left(r_{t}-r_{t}^{*}\right)+\zeta_{t, k},
$$

where $X_{t}^{k}=\sum_{i=0}^{k-1} X_{t-i}$ denotes order flow during the past $k$ days, and $\beta_{2} \Delta^{k}\left(r_{t}-r_{t}^{*}\right)+\zeta_{t, k}$ identifies the impact of public news arriving during the same period. Thus, the rate of depreciation over $k$ days will be well-approximated by the cumulative effects of order flow, $X_{t, k}$, and the arrival of public news. Figure 2 shows that there are many instances where $s_{t}-s_{t-k} \cong \beta_{1} X_{t}^{k}$ for significant horizons $k$. This evidence should help dispel the notion that micro-based models have little to say about exchange-rate behavior over macro-relevant time horizons.

The second feature concerns the dynamics of order flow. The plots of cumulative order flow in Figure 2 display no significant mean reversion because there is no detectable serial correlation in daily order flows. This feature of the data is important because the empirical specification in (22) assumes that realizations of daily order flow represent news to dealers. Thus daily order flow must be serially uncorrelated if the results in Table 1 are to be consistent with the predictions of the PS model.

The estimates in Table 1 are based on daily data from the Reuters D2000-1 trading platform the dominant trading platform in 1996. Evans (2002) reported similar results studying intradaily data from the same source. Since 1996 the electronic brokers EBS and Reuters D2000-2 have taken over as the preferred medium for interdealer trading. However, the basic mechanism in the PS model still applies: interdealer trade is driven by dealers wishing to use the information they obtain from filling the currency orders of their customers. Research using data from the electronic brokers show that the results in Table 1 are robust to both frequency and sample period. Payne (2003), 
Daníelsson and Love (2006) and Berger et al. (2008) find similar results in intraday analysis, while Breedon and Vitale (2010), Killeen et al. (2006), Chinn and Moore (2009), and Berger et al. (2008) confirm the results for daily to quarterly frequencies.

The strong empirical link between interdealer order flows and daily changes in the spot exchange rate extends to different currencies with lower levels of liquidity than the deutschemark, euro and yen. Evans and Lyons (2002c) study several smaller European currencies, Smyth (2009) examines the Australian and New Zealand dollar markets while Scalia (2008) and Menkhoff and Schmeling (2008) study emerging markets like Czech koruna and Russian ruble.

In the PS model interbank order flow conveys price-relevant information to dealers that initially entered the market in dispersed form via the customer orders received by individual dealers. Consequently, if interdealer order flow is a proximate driver of exchange rates, as the studies cited above suggest, we should expect to find that customer order flows also have explanatory power in accounting for exchange-rate changes. This is indeed the case. Marsh and O'Rourke (2005) find such a result for major currencies, King et al. (2010), Bjønnes et al. (2005), and Rime (2001) for small open economies, and Gyntelberg et al. (2009), Onur (2008) and Wu (2007) for emerging markets.

The majority of the studies cited above use regressions similar to the Evans and Lyons regression in equation (22). Some, like Payne (2003) and Menkhoff and Schmeling (2008) use the SVARapproach of Hasbrouck (1991); and some, like Chinn and Moore (2009), Killeen et al. (2006) and Bjønnes et al. (2005), use the framework of cointegration. Despite these differences, all the studies conclude that positive order flow significantly leads to an appreciation of the foreign currency, and that variations in order flow are a major contributor to the variance of exchange-rate changes. To repeat: This is true both for major currencies and emerging market currencies, for interbank and for customer order flows, for recent data samples as well as data from mid 1990s, and for exchange-rate variations at intraday to quarterly frequencies.

Order flows and Macro Data Releases Empirical micro-based research on the effects of macro data release has taken several different forms. Love and Payne (2008) study transaction prices and order flows from the Reuters electronic brokerage system to study the impact of data releases on trading in the EUR/USD, EUR/GBP and GBP/USD over 10 months in 1999 and 2000. When they use estimates of a VAR to compare the total effects of data releases on spot rate changes with the indirect effects induced by order flows, they find that the indirect effects contribute between $30 \%$ and $60 \%$ of the variance. In other words, a significant fraction of the price-relevant information contained in data release becomes impounded into spot rates via order flow.

Evans and Lyons (2008) develop an alternative econometric model to study the intraday response of spot rates and order flows to data releases. In particular, consistent with the PS model discussed above, they allow the arrival of a data release to affect the process through which the information carried by order flow is impounded to FX quotes. Their results indicate that order flow contributes more to spot-rate adjustment following macro data releases than at other times. This is not what one would expect. If macro releases primarily contain precise information that is directly impounded into 
dealers' quotes, order flow should contribute less to spot rate dynamics in the period following the release than at other times. In contrast, the results in Evans and Lyons (2008) strongly suggest that a macro data release triggers trading that reveals new information that affects spot rates indirectly. ${ }^{10}$

Evans and Lyons (2008) also use the PS model to examine the effects of data releases in daily data. As above, data releases affect dealers quotes directly, and indirectly via their impact on order flows. Evans and Lyons (2008) estimate that more than one third of the total variance in daily spot rate changes can be related to the direct and indirect effects of macro data releases and other news sources, with indirect effects contributing roughly $60 \%$ more than the indirect effects. These estimates clearly indicate that the indirect effects of news operating via order flow are an important component of spot rate dynamics.

The results from conventional event studies suggest that all the detectable exchange-rate effects of data releases occur within a few minutes. However, this perspective changes when we account for the indirect effects of data releases on exchange rates operating via order flows. Using daily disaggregated customer order flow from Citibank, Evans and Lyons (2005a) show that the indirect effects from news may take up to week. The use of dealer-data to customer data in this study is important for at least two reasons: First, since order flow from customers is proprietary information, one would expect that it takes longer for customer trades to become common knowledge than for interdealer trades. Second, customers have more first-hand information than dealers about the realtime state of the economy, and hence their trading may be especially informative about the impact of macro releases. Evans and Lyons (2005a) find that much of the protracted response of exchange rates to news comes via the order flows of leveraged investors - an end-user class that conducts extensive analysis of news and the macroeconomy.

Further Implications A number of studies have found that past changes in FX prices have forecasting power for order flows. For example, Daníelsson and Love (2006) find highly significant coefficient estimates on lagged price changes in the order flow equation of their simultaneous equation model. There is also evidence of forecastability of customer flows at the daily frequency. Sager and Taylor (2008) find that daily customer order flow data from JPMorgan Chase can be predicted with prior foreign exchange returns. Do these results establish that order flows largely reflect the actions of dealers and customer following feedback trading strategies, and as such convey rather little new price-relevant information?

The answer to this question is clearly no. From a theoretical perspective, changes in FX prices can be solely driven by the information conveyed by order flow which is itself forecastable using past changes in FX prices. Indeed the PS model has precisely this combination of features. Interdealer order flows are the proximate driver of all the intraday changes in FX prices, but the interdealer order flow depends in part on the public pre-existing FX holdings that are correlated with lagged FX price changes. The key point here is that it is the unexpected portion of order flow that conveys

\footnotetext{
${ }^{10}$ These findings relate to earlier results in Payne (2003) and Evans and Lyons (2002b) showing how the price-impact of order flow varies with the level of trading intensity.
} 
the price-relevant information to dealers, so the fact that order flow is to some extent forecastable does not negate its role as a conveyor of price-relevant information.

That said, predictability in order flow can complicate inferences in regressions like (22) because the use of actual order flow rather than its unpredictable component introduces "measurement error". Daníelsson and Love (2006) show that when one takes account of this "measurement error" the impact from order flow is even higher. Intuitively, only the unexpected component of order flow conveys price-relevant information, so the estimated coefficient on total order flow is biased downwards. Bjønnes et al. (2005) and Killeen et al. (2006) provide some related evidence. They use error correction models to study whether order flows and exchange-rate changes are forecastable using the gap between the current rate and the rate implied by cumulated past order flows: $S_{t}-$ $\lambda_{\mathrm{x}} X_{t}^{\infty}$. They find that the gap has forecasting power for future exchange-rate changes but not order flows. These results are consistent with the notion that order flows are a proximate determinant of exchange-rate changes because they convey information.

The PS shifts model also sheds light on the relationship between order flows and portfolio holdings. Recall that the risks of holding FX overnight are more efficiently shared by investors than by dealers, so the price of FX quoted by dealers at the end of each day reflects their desire to close out their existing FX positions. Now dealers have sufficient information to precisely infer the price at which investors can be induced to hold the existing stock of FX. This means that the aggregate FX holdings of investors at the end of day $t, A_{t}$, follow $A_{t}=A_{t-1}+Y_{t}$, where $Y_{t}$ is aggregate foreign income investors receive on day $t$. So an estimate of the day $t$ order flow computed from the change in the foreign currency holdings of investors would be $A_{t}-A_{t-1}=Y_{t}$. This estimate differs from the actual order flow that drives spot rate changes on day $t$. For example, on non-release days equation (16) implies that aggregate customer order flow from round I trading is $\sum_{d} Z_{d, t}^{\mathrm{I}}=\beta Y_{t}$, where $\beta<0$. Thus, the position-based estimate of order flow is perfectly negatively correlated with true order flow. This problem is not specific to the PS model. It occurs whenever this is a frequency miss-match between transactions and the portfolio positions recorded in the data. Unfortunately, it is often overlooked when researchers use portfolio positions to estimate order flows. (see, for example, Froot and Ramadorai (2005)).

Accurate estimates of order flow also require information on the initiator of trade. Often this information is unavailable, but it can be inferred from institutional knowledge. For example, for typical dealer-customer transactions (e.g., a mutual fund or corporation) the initiative will come from the end user contacting the bank to ask for some FX quotes. Such inferences about the initiator of trade are impossible in the wholesale interbank market because trade can be initiated by any bank (either directly or indirectly via a market order on an electronic brokerage system). If trading takes place via a limit order market, Evans (2011) shows it is impossible to accurately identify order flow from data on portfolio holdings without further information on how traders choose between limit and market orders. ${ }^{11}$

\footnotetext{
${ }^{11}$ Evidence from interbank dealers indicate that dealers use market orders when they regard themselves as informed [ see, e.g., Bjønnes and Rime (2005)]
} 
Although transactions in the retail FX market are typically initiated by end users, two features of the market complicate the identification of customer order flow. First, in the past few years some banks have given their largest customers direct access to the electronic brokerage systems that now dominate trading in the interbank market (e.g., EBS and Reuters 3000). These end-users now can submit both market and limit orders on the same terms as any bank, so it is no longer safe to assume that they are the initiators of every trade. The second complication arises from the use of stop-loss and take-profit orders by end-users. These price-contingent orders provide end-users with a close substitute to the limit orders available on the interbank brokerage systems, but make the identification of order flow from changes in portfolio holdings just as difficult as when end-users can submit limit orders. ${ }^{12}$

The PS model also clarifies how spot rates and order flows should be linked in the long run. Following the work of Hasbrouck (1991), it is common to equate permanent changes in asset prices with the embedding of information. For example, Payne (2003) estimates that more than $40 \%$ to the variance of permanent changes in log spot rates is attributable to order flow shocks. Consistent with this finding, Killeen et al. (2006) and Chinn and Moore (2009) show that cumulative interdealer order flow is cointegrated with log spot rates. Using customer data Bjønnes et al. (2005) find evidence of cointegration, while Froot and Ramadorai (2005) and Boyer and van Norden (2006) do not.

The PS model helps make sense of these results. In particular, the model implies that spot rates should be cointegrated with cumulated interdealer order flow because unexpected order flow permanently changes dealers quotes. At the same time, the PS model shows that there is no cointegrating relationship between spot rate and aggregate cumulated customer order flow. In equilibrium investors hold the existing shock of FX at the end of each day, so cumulated customer order flows aggregated over rounds I and III are zero. This feature will be present in any micro-based model where dealers seek to allocate risk efficiently between themselves and other market participants. Consequently, a failure to find cointegration between cumulated customer order flows and spot rates is actually consistent with efficient risk sharing but uninformative about the role order flow plays in the determination of spot rates. This implication need not apply to disaggregated customer flows. For example, suppose one group of end-users is over-represented in round-I trading and underrepresented in round II. In that case, spot rates could be cointegrated with cumulated order flows of different end-users, as indicated by the results in Bjønnes et al. (2005).

Many papers interpret the empirical relation between exchange rates and order flows in terms of liquidity or information concerning fundamentals. For example, Bjønnes et al. (2007) and Marsh and O'Rourke (2005) argue that differential price-impact of order flow across counterparties is an indication that order flow carries fundamental information, while Froot and Ramadorai (2005) and

\footnotetext{
${ }^{12}$ The presence of the price-contingent orders need not lead to inaccurate estimates of order flow if purchases and sales of foreign currency implied by take-profit and stop-loss orders are well-balanced over the range for spot rates in the data sample. Unfortunately, this does not appear to always be the case. Osler (2003) found that stop-loss buy orders are more strongly clustered above than below trigger points with round numbers, and the opposite is true for stop-loss sell orders. This means that estimates of order flow derived from portfolio holdings may be less accurate when the spot rate is the neighborhood a trigger point with round numbers.
} 
Berger et al. (2008) suggest that the explanatory power of order flow primarily stems from liquidity disruptions. Assessing the validity of these interpretations is very difficult without a theoretical model that allows for both possibilities. In particular, the PS model shows how order flow conveys information about the hedging demands of investors (i.e., non-fundamental information) that has both short- (intraday) and long-term exchange-rate effects. Thus, classifying the type of information conveyed by order flow according to the persistence of its effects on FX prices is unlikely to be accurate. More generally, risk-averse dealers need to be compensated for the risks of providing liquidity to investors when their trades (in aggregate) convey information on fundamentals such as future interest rates. Consequently, it is hard to conceive of an empirically-relevant trading model where a clear dichotomy exists between liquidity and information effects.

\section{Exchange Rates, Order Flows and the Macroeconomy}

Microstructure exchange-rate models, such as the PS model, are silent on the potential links between the macro economy and order flows because they focus on the details of currency trading between different market participants rather than the macroeconomic factors that ultimately drive the individual trades. More specifically, all the information conveyed by order flow in the PS model concerns the risk premium dealers embed in their spot rate quotes. Thus, from the perspective of the PS model, the correlation between depreciation rates and order flows observed in the data is attributable to the role order flow plays in driving the last term on the right hand side of (6):

$$
\begin{aligned}
\Delta s_{t+1} & =r_{t}-r_{t}^{*}-\left(1-\mathbb{E}_{t}\right) \Delta\left(r_{t+1}-r_{t+1}^{*}\right) \\
& +\frac{\rho}{1-\rho}\left(\mathbb{E}_{t+1}-\mathbb{E}_{t}\right) f_{t+1}+\frac{1}{1-\rho}\left(\mathbb{E}_{t+1}-\mathbb{E}_{t}\right) \sum_{i=2}^{\infty} \rho^{i-1} \Delta f_{t+i} \\
& +\delta_{t}-\left(\mathbb{E}_{t+1}-\mathbb{E}_{t}\right) \sum_{i=1}^{\infty} \rho^{i-1} \delta_{t+i}
\end{aligned}
$$

Clearly, this is a rather narrow perspective. The observed correlation between depreciation rates and order flows could also reflect the fact that order flow conveys information about current and future fundamentals (i.e., via the terms in the second row above). To address this possibility, recent microbased research focuses on the role order flow plays in conveying macro information. This research builds on two central ideas: First, only some of the macro information relevant for the current spot rate is publicly known at any point in time. Other information is present in the economy, but it exists in a dispersed microeconomic form. Second, since the spot rate literally is the price of FX quoted by dealers, it will only reflect dispersed information once it has been assimilated by dealers - a process that takes place via trading. Below we provide an overview of a micro-based model developed by Evans and Lyons (2009) that incorporates these ideas and discuss its empirical implications. 


\subsection{A Micro-Based Macro Model}

The economy comprises two countries populated by a continuum of risk-averse agents, indexed by $n \in[0,1]$; and D risk-averse dealers who act as marketmakers in the spot FX market. We will refer to the home and foreign countries as the US and Europe, so the log spot exchange rate, $s_{t}$, denotes the dollar price of euros. The only other actors in the model are the central banks (i.e., The Federal Reserve (FED) and the European Central Bank (ECB)), who conduct monetary policy by setting short-term nominal interest rates, $r_{t}$ and $r_{t}^{*}$.

\subsubsection{An Overview}

The model focuses on the currency trades between agents and dealers at a weekly frequency. At the start of week $t$, all dealers and agents observe a data release that provides information on the state of the economy several weeks earlier. Let $z_{t}$ denote a vector of variables that completely describe the state of the macroeconomy in week $t$. This vector contains variables that are directly observable, like short-term interest rates, and others that only become publicly known with a lag. Each agent $n$ also receives private information concerning his or her current microeconomic environment: $z_{t}^{n}=z_{t}+v_{t}^{n}$, where $v_{t}^{n}=\left[v_{i, t}^{n}\right]$ is a vector of agent-specific shocks with the property that $\int_{0}^{1} v_{i, t}^{n} d n=0$ for all $i$. Notice that the $z_{t}^{n}$ vector represents dispersed private information about macro conditions across the world economy.

Next, all dealers quote a log USD/EUR spot price equal to

$$
s_{t}=\mathbb{E}_{t}^{\mathrm{D}} s_{t+1}+r_{t}^{*}-r_{t}-\delta_{t},
$$

where $\mathbb{E}_{t}^{\mathrm{D}}$ denotes expectations conditioned on the common information available to all dealers at the start of week $t$. This information set includes the histories of interest rates and data releases, and the order flows from earlier currency trading. Macroeconomic conditions affect dealers quotes in (23) via their affects on current monetary policy (i.e., $r_{t}^{*}-r_{t}$ ), and via $\mathbb{E}_{t}^{\mathrm{D}} s_{t+1}$ insofar as these expectations are affected by dealers' forecasts for the future interest differential. These forecasts are assumed to incorporate a view on how central banks react to changes in the macroeconomy, as shown in equation (2) (with $\mathbb{E}_{t}^{\mathrm{D}}$ replacing $\mathbb{E}_{t}$ ):

$$
\mathbb{E}_{t}^{\mathrm{D}}\left(\hat{r}_{t+i}-r_{t+i}\right)=\left(1+\gamma_{\pi}\right) \mathbb{E}_{t}^{\mathrm{D}}\left(\Delta p_{t+1+i}^{*}-\Delta p_{t+1+i}\right)+\gamma_{y} \mathbb{E}_{t}^{\mathrm{D}}\left(y_{t+i}^{*}-y_{t+i}\right)-\gamma_{q} \mathbb{E}_{t}^{\mathrm{D}} q_{t+i}
$$

As in the PS model, the risk premium in (23) is determined by the requirements of efficient risk-sharing. More specifically, in an economy where their is a finite number of risk-averse dealers

and a continuum of risk-averse agents, dealers will choose $\delta_{t}$ such that their expected holdings of risky currencies at the end of week $t$ are zero. We assume that all dealers are located in the US. They therefore choose the risk premium, $\delta_{t}$, such that their expected holdings of euros at the end of week $t$ equal zero. These holdings are determined by the history of order flow from all agents. In particular, let $X_{t+1}$ denote the aggregate of all orders from agents for euros received by dealers 
during week $t$, so $I_{t+1}=-\sum_{i=0}^{\infty} X_{t+1-i}$ denotes the euro holdings of all dealers at the end of week- $t$ trading. ${ }^{13}$ Efficient risk-sharing requires that dealers chose a value for $\delta_{t}$ such that

$$
\mathbb{E}_{t}^{\mathrm{D}} I_{t+1}=0
$$

Dealers stand ready to fill the foreign currency orders of agents at their quoted price of $s_{t}$. Once agent $n \in[0,1]$ observes $s_{t}$, they place their currency order with a dealer to fill their demand for euros. The order flow for euros from agent $n$ is therefore $\alpha_{t}^{n}-\alpha_{t-1}^{n}$ where $\alpha_{t}^{n}$ denotes the week- $t$ euro demand by agent $n$. This demand is given by

$$
\alpha_{t}^{n}=\alpha_{s}\left(\mathbb{E}_{t}^{n} \Delta s_{t+1}+r_{t}^{*}-r_{t}\right)+h_{t}^{n},
$$

where $\alpha_{s}>0$ and $\mathbb{E}_{t}^{n}$ denotes expectations conditioned on the information available to agent $n$ after the spot rate is quoted at the start of week $t$. The demand for euros depends on the log excess return expected by the agent and a hedging term, $h_{t}^{n}$, that represents the influence of all other factors. Without loss of generality, we may assume that $h_{t}^{n}=\alpha_{z} z_{t}^{n}$, for some vector $\alpha_{z}$, where the vector $z_{t}^{n}$ describes the microeconomic environment of agent $n$. The aggregate demand for euros by agents is thus given by

$$
\alpha_{t}=\int_{0}^{1} \alpha_{t}^{n} d n=\alpha_{s}\left(\overline{\mathbb{E}}_{t}^{n} s_{t+1}-s_{t}+r_{t}^{*}-r_{t}\right)+h_{t},
$$

where $\overline{\mathbb{E}}_{t}^{n}$ denotes the average of agents' expectations, $\overline{\mathbb{E}}_{t}^{n} s_{t+1}=\int_{0}^{1} \mathbb{E}_{t}^{n} s_{t+1} d n$, and $h_{t}=\alpha_{z} \int_{0}^{1} z_{t}^{n} d n=$ $\alpha_{z} z_{t}$. Notice that the aggregate hedging demand, $h_{t}$, depends on the state of the macroeconomy, $z_{t}$.

For the remainder of the week, dealers trade among themselves. The model abstracts from the details of interdealer trade. Instead, consistent with the PS model, it assumes that all dealers learn the aggregate order flow that resulted from the earlier week- $t$ trades between agents and dealers. This order flow is determined by

$$
X_{t+1}=\alpha_{t}-\alpha_{t-1} .
$$

Equations (27) and (28) imply that order flow is driven by changes in the average of agents' expectations concerning future excess returns and the change in the aggregate hedging demand.

Several features distinguish this model from macro exchange-rate models. First, it incorporates the fact that dealers and agents have incomplete and different information about the current state of the macroeconomy. In contrast, traditional macro models assume that the full current state is common knowledge. Second, the spot rate includes a risk premium that dealers choose to manage risk efficiently. The factors that drive this risk premium in equilibrium are very different from those determining the risk premium in macro models. Third, the model identifies the determinants of order flows and the role they play as a driver of exchange rates. In contrast, currency-trading patterns play no role in exchange-rate determination in macro models.

\footnotetext{
${ }^{13}$ We identify the order flow from week- $t$ trading with a subscript of $t+1$ to emphasize the fact that dealers cannot use the information it conveys until the start of week $t+1$.
} 


\subsubsection{Equilibrium}

An equilibrium in this model comprises a sequence of spot rates and market-clearing order flows that support and are supported by the endogenous evolution of dealers' common information and agents' private information. Recall that dealers and agents observe current interest rates and the data releases containing information on past macro conditions. Dealers also obtain information from their observations on order flow that is endogenously determined by the trading decisions of agents. Similarly, each agent observes the endogenously determined spot rate together with their microeconomic environment.

Solving for equilibrium spot rates and order flows is complex. But, so long as public information about the current state of macroeconomy is incomplete, equilibrium order flows provide dealers with information about the macroeconomy that they will embed in the spot rate quotes; information that was initially dispersed across agents as their observations on $z_{t}^{n}$.

In equilibrium, the weekly depreciation rate takes the same form as (6):

$$
\begin{aligned}
\Delta s_{t+1} & =r_{t}-r_{t}^{*}-\left(1-\mathbb{E}_{t}^{\mathrm{D}}\right) \Delta\left(r_{t+1}-r_{t+1}^{*}\right) \\
& +\frac{\rho}{1-\rho}\left(\mathbb{E}_{t+1}^{\mathrm{D}}-\mathbb{E}_{t}^{\mathrm{D}}\right) f_{t+1}+\frac{1}{1-\rho}\left(\mathbb{E}_{t+1}^{\mathrm{D}}-\mathbb{E}_{t}^{\mathrm{D}}\right) \sum_{i=2}^{\infty} \rho^{i-1} \Delta f_{t+i} \\
& +\delta_{t}-\left(\mathbb{E}_{t+1}^{\mathrm{D}}-\mathbb{E}_{t}^{\mathrm{D}}\right) \sum_{i=1}^{\infty} \rho^{i-1} \delta_{t+i} .
\end{aligned}
$$

Thus, order flow has the potential to drive the depreciation rate by revising dealers expectations about fundamentals and the risk premia, $\delta_{t}$.

Recall that dealers choose $\delta_{t}$ so that $\mathbb{E}_{t}^{\mathrm{D}} I_{t+1}=0$ where $I_{t+1}=I_{t}-x_{t+1}$, and market clearing requires that the aggregate order flow received by dealers during week- $t$ trading must equal the aggregate change in the demand for euros across all agents: $x_{t+1}=\alpha_{t}-\alpha_{t-1}$. These two conditions jointly imply that $I_{t+1}+\alpha_{t}=I_{t}+\alpha_{t-1}=I_{1}+\alpha_{0}$. For clarity, we normalize $I_{1}+\alpha_{0}$ to equal zero, so efficient risk-sharing requires that $0=\mathbb{E}_{t}^{\mathrm{D}} \alpha_{t}$. Combining this restriction with (27) gives

$$
0=\alpha_{s} \mathbb{E}_{t}^{\mathrm{D}}\left(\overline{\mathbb{E}}_{t}^{n} s_{t+1}-s_{t}+r_{t}^{*}-r_{t}\right)+\mathbb{E}_{t}^{\mathrm{D}} h_{t}
$$

Since $\mathbb{E}_{t}^{\mathrm{D}} \Delta s_{t+1}+r_{t}^{*}-r_{t}=\delta_{t}$ from equation (23), and $\mathbb{E}_{t}^{\mathrm{D}} \overline{\mathbb{E}}_{t}^{n} s_{t+1}=\mathbb{E}_{t}^{\mathrm{D}} s_{t+1}+\mathbb{E}_{t}^{\mathrm{D}}\left(\overline{\mathbb{E}}_{t}^{n} s_{t+1}-s_{t+1}\right)$ by definition, the first term on the right of (30) is equal to $\alpha_{s} \delta_{t}+\alpha_{s} \mathbb{E}_{t}^{\mathrm{D}}\left(\overline{\mathbb{E}}_{t}^{n} s_{t+1}-s_{t+1}\right)$. We may therefore rewrite equation (30) as

$$
\delta_{t}=\mathbb{E}_{t}^{\mathrm{D}}\left[s_{t+1}^{e}-\frac{1}{\alpha_{s}} h_{t}\right]
$$

where $s_{t+1}^{e}=s_{t+1}-\overline{\mathbb{E}}_{t}^{n} s_{t+1}$.

Equation (31) shows that dealers' choice for the risk premium depends on their estimates of: (i) the aggregate hedging demand for euros, $\mathbb{E}_{t}^{\mathrm{D}} h_{t}$; and (ii) the average error agents make when forecasting next week's spot rate, $s_{t+1}^{e}$. Intuitively, dealers lower the risk premium when they anticipate a rise in the aggregate hedging demand for euros because the implied fall in the excess 
return agents' expect will offset their desire to accumulate larger euro holdings. Dealers also reduce the risk premium to offset agents' desire to accumulate larger euro holdings when they are viewed as being too optimistic (on average) about the future spot rate; that is when $\mathbb{E}_{t}^{\mathrm{D}} s_{t+1}<\mathbb{E}_{t}^{\mathrm{D}} \overline{\mathbb{E}}_{t}^{n} s_{t+1}$.

In equilibrium, the aggregate order flow dealers observe at the end of week- $t$ trading reflects the change in aggregate demand for foreign currency by agents between weeks $t-1$ and $t: X_{t+1}=$ $\alpha_{t}-\alpha_{t-1}$. Since dealers know the history of order flow and $\alpha_{t-1}=\sum_{i=0}^{\infty} X_{t-i}$ by market clearing, $\alpha_{t-1} \in \Omega_{t}^{\mathrm{D}}$. Consequently, unexpected order flow from week- $t$ trading can be written as

$$
X_{t+1}-\mathbb{E}_{t}^{\mathrm{D}} X_{t+1}=\alpha_{z}\left(z_{t}-\mathbb{E}_{t}^{\mathrm{D}} z_{t}\right)+\alpha_{s}\left(\overline{\mathbb{E}}_{t}^{n} s_{t+1}-\mathbb{E}_{t}^{\mathrm{D}}\left[\overline{\mathbb{E}}_{t}^{n} s_{t+1}\right]\right)
$$

Thus order flow contributes new information about the current macroeconomic conditions, $z_{t}$, via the aggregate hedging demand, $h_{t}-\mathbb{E}_{t}^{\mathrm{D}} h_{t}=\alpha_{z}\left(z_{t}-\mathbb{E}_{t}^{\mathrm{D}} z_{t}\right)$, and about the average of agents' spot rate forecasts, $\overline{\mathbb{E}}_{t}^{n} s_{t+1}$. These forecasts will embed agents private expectations concerning future interest rates, and the macroeconomic conditions that affect monetary policy.

Equations (31) and (32) shed light on the role heterogenous information plays in the behavior of the risk premium and order flow. In particular, if agents and dealers have the same spot rate forecasts (i.e., $\mathbb{E}_{t}^{\mathrm{D}} s_{t+1}=\mathbb{E}_{t}^{n} s_{t+1}$ for all $\left.n \in[0,1]\right), \mathbb{E}_{t}^{\mathrm{D}} s_{t+1}^{e}=0$ and $\overline{\mathbb{E}}_{t}^{n} s_{t+1}=\mathbb{E}_{t}^{\mathrm{D}}\left[\overline{\mathbb{E}}_{t}^{n} s_{t+1}\right]$ so (31) and (32) imply that $\delta_{t}=-\frac{1}{\alpha_{s}} \mathbb{E}_{t}^{\mathrm{D}} h_{t}$ and $X_{t+1}-\mathbb{E}_{t}^{\mathrm{D}} X_{t+1}=h_{t}-\mathbb{E}_{t}^{\mathrm{D}} h_{t}$. Here the risk premium only varies with dealers' estimate of the aggregate hedging demand and order flow simply reflects their

estimation error. Under other circumstances, heterogeneity among dealers' and agents spot-rate forecasts contribute to the variations in the risk premium via $\mathbb{E}_{t}^{\mathrm{D}} s_{t+1}^{e}$ and unexpected order flow via $\alpha_{s}\left(\overline{\mathbb{E}}_{t}^{n} s_{t+1}-\mathbb{E}_{t}^{\mathrm{D}}\left[\overline{\mathbb{E}}_{t}^{n} s_{t+1}\right]\right)$.

\subsection{Empirical Implications}

Order Flows and Current Macro Conditions Consider the behavior or excess returns, $e r_{t+1}=$ $\Delta s_{t+1}+r_{t}^{*}-r_{t}$. Combining this definition with (29) and (31) gives

$$
e r_{t+1}=\delta_{t}+\left(1-\mathbb{E}_{t}^{\mathrm{D}}\right)\left(r_{t+1}^{*}-r_{t+1}\right)+\left(\mathbb{E}_{t+1}^{\mathrm{D}}-\mathbb{E}_{t}^{\mathrm{D}}\right) \sum_{i=2}^{\infty} \rho^{i-1}\left(f_{t+i}-\frac{1}{\rho} s_{t+i}^{e}-\frac{1}{\rho \alpha_{s}} h_{t+i-1}\right) .
$$

Notice that the second and third terms on the right-hand-side depend on the flow of information reaching all dealers between the start of weeks $t$ and $t+1$. This information flow comprises observations on current interest rates, data releases on past macro variables, and order flow from week- $t$ trading, $X_{t+1}$. Equation (33) implies that any of these information sources will affect the excess returns insofar as they convey new information on current monetary policy, future fundamentals and the risk premia. Thus the model attributes the strong correlation between foreign currency returns and order flows observed in the data to the important role order flow plays in this information transmission process.

Following Evans (2010), we can examine this implication of the model with a two step regression procedure. In the first step we regress a macro variable $\varkappa_{t}$ on the cumulation of current and past order 
flows, $X_{t+1}^{\infty}=\sum_{i=0}^{\infty} X_{t+1-i}$. Under efficient risk-sharing $X_{t+1}^{\infty}=X_{t+1}-\mathbb{E}_{t}^{\mathrm{D}} X_{t+1}$, so the regression coefficient on $X_{t+1}^{\infty}$ should be statistically significant if unexpected order flow from week- $t$ trading contains information about macro variable $\varkappa_{t}$. In the second step we regress excess returns on the predicted values from the first stage. The estimated slope coefficient in this regression should be statistically significant when the information concerning $\varkappa_{t}$ conveyed by order flow is price-relevant.

Table 2 reproduces the results from estimating the second stage regression as reported in Evans (2010). The dependent variable is the excess return on the USD/EUR rate over a 4 week horizon. The independent variables in Panel A are the predicted values from regressions of GDP growth, CPI inflation and M1 growth in the US and Germany on cumulated customer order flows for euros received by Citibank. In panel B the independent variables are the differences between the predicted values for the German and US macro variables. The regressions are estimated at the weekly frequency in data from January 1993 to June 1999.

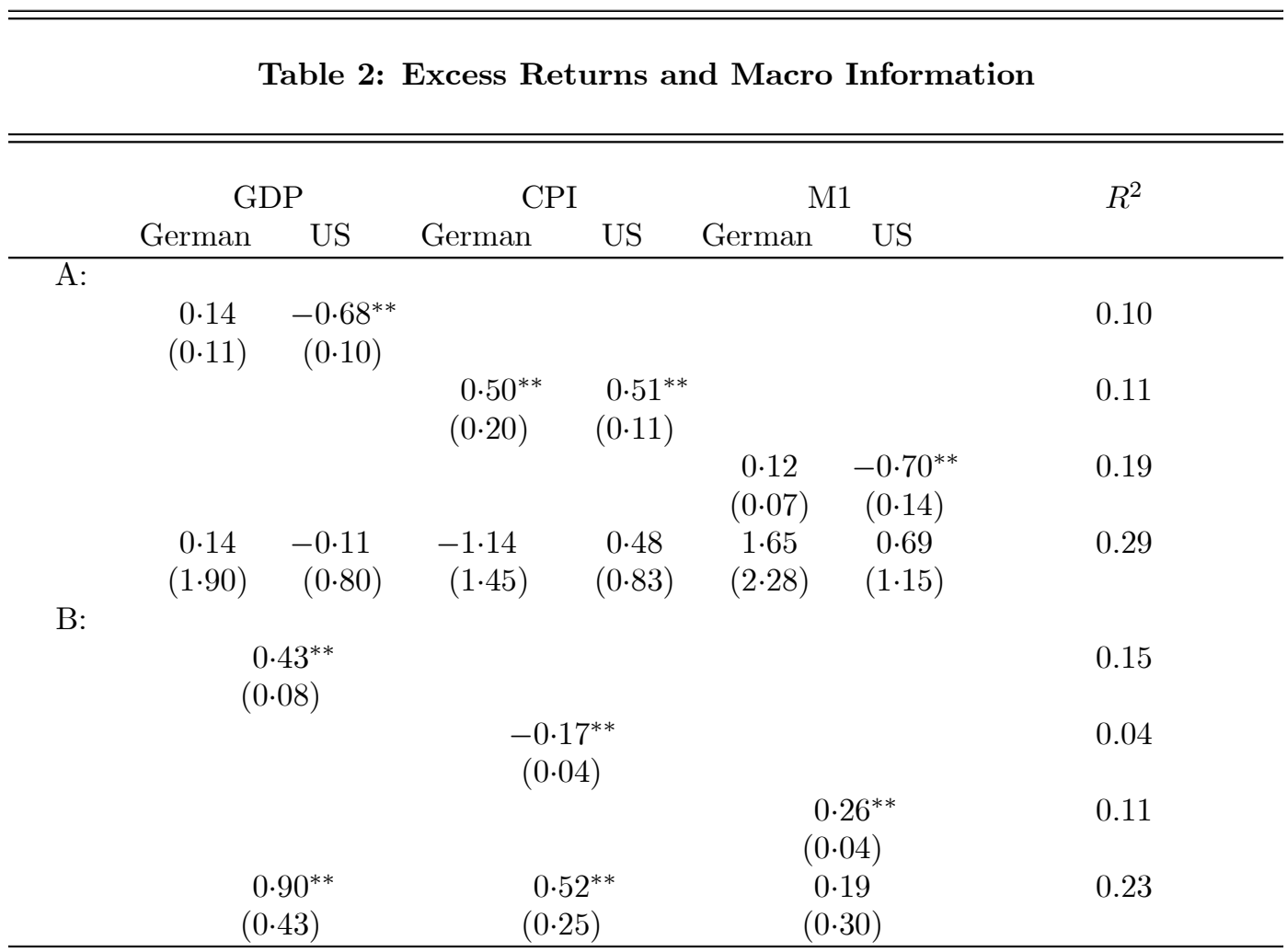

Notes: The table reports slope coefficients and standard errors from the second stage regression using the predicted values for the variables listed at the head of each column. Estimates are calculated at the weekly frequency. The standard errors correct for heteroskedasticity. and an MA(3) error process. Statistical significance at the $5 \%$ and $1 \%$ level is denoted by $*$ and $* *$. Source: Evans (2010)

The results in Table 2 provide strong support for the idea that order flows convey price-relevant information about GDP, prices and the money stock. The slope coefficients for German inflation, US 
GDP growth, inflation and monetary growth are all significant at the $1 \%$ level. Insofar as spot rates reflect the difference between US and EU monetary policy, order flows should carry more pricerelevant information about the difference in macroeconomic conditions between countries. This seems to be the case. As Panel B shows, the slope coefficients on the predicted values for GDP growth and inflation are highly significant. These findings are supported by results in Rime et al. (2010). They show that interdealer order flow has forecasting power for specific macro data releases scheduled in the next week. For example, positive euro order flow forecasts a higher than previously anticipated data release in cases where positive releases are associated with an appreciation of the euro.

Order Flows and Future Macro Conditions The model also holds implications for the links between the dynamics of spot rates, order flows and the future evolution of the macro economy. In particular, dealers' equilibrium quotes can be written as

$$
s_{t}=\bar{s}_{t}+\frac{1}{1-\rho} \mathbb{E}_{t}^{\mathrm{D}} \sum_{i=1}^{\infty} \rho_{t+i}^{i}\left(\Delta f_{t+i}-\Delta \delta_{t+i}\right)
$$

where

$$
\bar{s}_{t}=\left(r_{t}^{*}-r_{t}\right)+\frac{\rho}{1-\rho} \mathbb{E}_{t}^{\mathrm{D}} f_{t}-\frac{1}{1-\rho} \delta_{t} .
$$

This equation splits the factors affecting dealers' spot rate quotes into two terms. Current conditions, such as interest rats and dealer's estimates of week- $t$ fundamentals affect dealers' quotes via $\bar{s}_{t}$. Expected changes in future conditions (i.e., inflation, the output gaps and the risk premium), affect the spot rate via the second term. It is this term that provides the link between spot rates, order flows and the future path of macro variables.

Equation (34) implies that $s_{t}-\bar{s}_{t}$ will have forecasting power for any future macro variable, $\varkappa_{t+\tau}$, if dealers expectations, $\mathbb{E}_{t}^{\mathrm{D}} \varkappa_{t+\tau}$, are correlated with $\mathbb{E}_{t}^{\mathrm{D}}\left(\Delta f_{t+i}-\Delta \delta_{t+i}\right)$. Intuitively, dealers will raise their spot rate quotes relative to $\bar{s}_{t}$ when their forecasts of future changes in fundamentals increase, so if these forecast are correlated with $\mathbb{E}_{t}^{\mathrm{D}} \varkappa_{t+\tau}$, variations in $s_{t}-\bar{s}_{t}$ will have forecast power for $\varkappa_{t+\tau}$. Equation (34) also implies that order flow should generally have incremental forecasting power for future macro variables beyond that contained in $s_{t}-\bar{s}_{t}$. To understand why, consider the following identity:

$$
\varkappa_{t+\tau}=\mathbb{E}_{t}^{\mathrm{D}} \varkappa_{t+\tau}+\left(\mathbb{E}_{t+1}^{\mathrm{D}}-\mathbb{E}_{t}^{\mathrm{D}}\right) \varkappa_{t+\tau}+\left(1-\mathbb{E}_{t+1}^{\mathrm{D}}\right) \varkappa_{t+\tau}
$$

The first term on the right identifies dealers' expectations concerning $\varkappa_{t+\tau}$ based on the information they use to quote spot rates at the start of week $t$. The second term identifies the revision in dealers' forecasts between the start of weeks $t$ and $t+1$. The incremental forecasting power of order flow comes from this term, which, by construction, is uncorrelated with $\mathbb{E}_{t}^{\mathrm{D}} \varkappa_{t+\tau}$. In particular, any information conveyed by $X_{t+1}-\mathbb{E}_{t}^{\mathrm{D}} X_{t+1}$ concerning $\varkappa_{t+\tau}$ will lead dealers to revise their forecasts of $\varkappa_{t+\tau}$.

This implication of the model can be examined with a regression of $\varkappa_{t+\tau}$ on $s_{t}$ and other vari- 
ables known to dealers at the start of week $t$ (as proxies for $\bar{s}_{t}$ ), and unexpected order flow from trades between dealers and agents during week $t$. The coefficients on the order flows should be statistically significant if they have incremental forecasting power for the macro variable in question. Furthermore, the portion of the predicted value for $\varkappa_{t+\tau}$ attributable to the order flows should make a significant contribution to the variance of $\varkappa_{t+\tau}$ if the information conveyed by the order flows is economically significant.

Figure 3 reproduces the plots from Evans and Lyons (2009) that show the variance contributions of Citibank's customer order flows together with $95 \%$ confidence bands for the six macro variables considered in Table 2 for horizons $\tau=1, . ., 26$ weeks. In five of the six cases, the contributions rise steadily with the horizon and are quite sizable beyond one quarter. The exception is U.S. GDP growth, where the contribution remains around $15 \%$ from the quarterly horizon onward. These plots clearly show that order flows have considerable forecasting power for the future flows of information concerning GDP growth, inflation and M1 growth at all but the shortest horizons. Clearly, then, these order flows are carrying significant information on future macroeconomic conditions.

Macro Drivers of the Risk Premium Micro-based models have novel implications concerning the behavior of excess currency returns that are related to the way dealers adjust the risk premium embedded in their FX quotes. To illustrate these implications, we combine the definition of excess returns with the identity, $s_{t+1}=\mathbb{E}_{t}^{\mathrm{D}} s_{t+1}+\left(s_{t+1}-\mathbb{E}_{t}^{\mathrm{D}} s_{t+1}\right)$, and (23) to give

$$
\begin{aligned}
e r_{t+2} & =\delta_{t+1}+s_{t+2}-\mathbb{E}_{t+1}^{\mathrm{D}} s_{t+2}, \\
& =\mathbb{E}_{t}^{\mathrm{D}} \delta_{t+1}+\left(\delta_{t+1}-\mathbb{E}_{t}^{\mathrm{D}} \delta_{t+1}\right)+\left(s_{t+2}-\mathbb{E}_{t+1}^{\mathrm{D}} s_{t+2}\right) .
\end{aligned}
$$

This decomposition of returns holds true in any micro-based model irrespective of what determines interests rates and the aggregate hedging demand for foreign currency. We can therefore use it to think about the possible sources of forecastability for future excess returns.

The right hand side of (36) identifies two channels through which forecastability can occur. The first operates via dealers' expectations of next week's risk premium, $\mathbb{E}_{t}^{\mathrm{D}} \delta_{t+1}$. Any variable known to the dealers at the start of week $t$ could potentially be correlated with $\mathbb{E}_{t}^{\mathrm{D}} \delta_{t+1}$, and hence have forecasting power for $e r_{t+2}$. Notice that this channel rules out any forecasting power for unanticipated order flow from week- $t$ trading because $X_{t+1}-\mathbb{E}_{t}^{\mathrm{D}} X_{t+1}$ cannot be correlated with $\mathbb{E}_{t}^{\mathrm{D}} \delta_{t+1}$. The second channel operates via the revision in dealer's estimate of the risk premium, $\delta_{t+1}-\mathbb{E}_{t}^{\mathrm{D}} \delta_{t+1}$. These revisions occur because dealers change their estimates of the aggregate hedging demand and/or the average error of agents forecasting the future spot rate. They may be triggered either by the arrival of public information at the start of week $t+1$ (e.g., an unanticipated change in interest rates or a macro announcement) or by the information conveyed by order flow from week $t$ trading, $X_{t+1}-\mathbb{E}_{t}^{\mathrm{D}} X_{t+1}$. In the latter case, order flow will have forecasting power for future excess returns. 


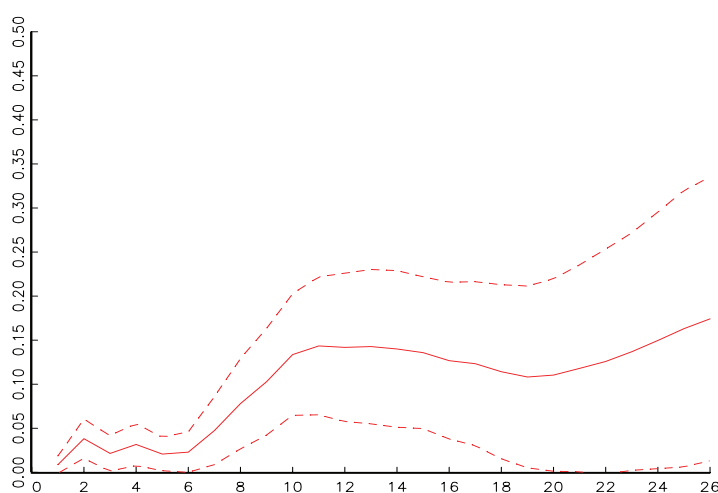

A: U.S. GDP Growth

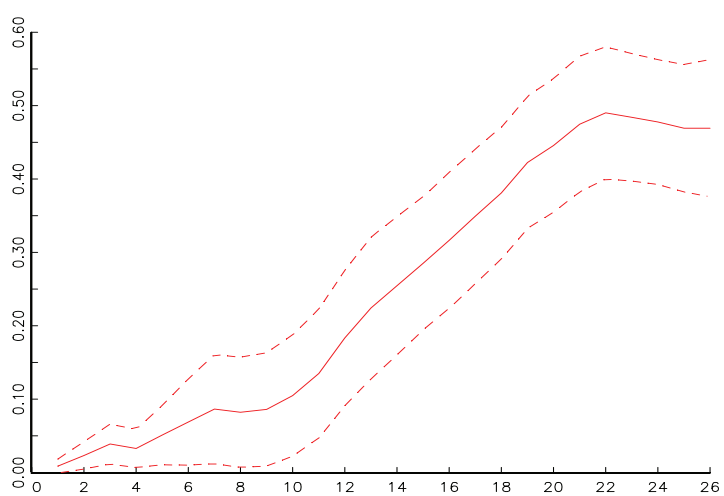

C: U.S. Inflation

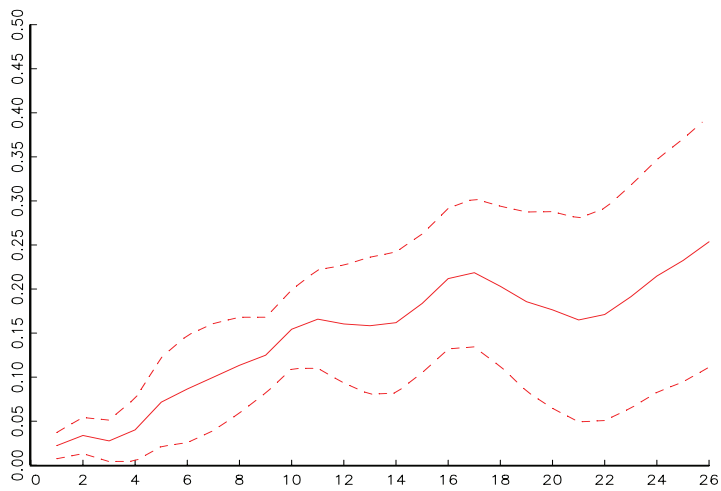

E: U.S. M1 Growth

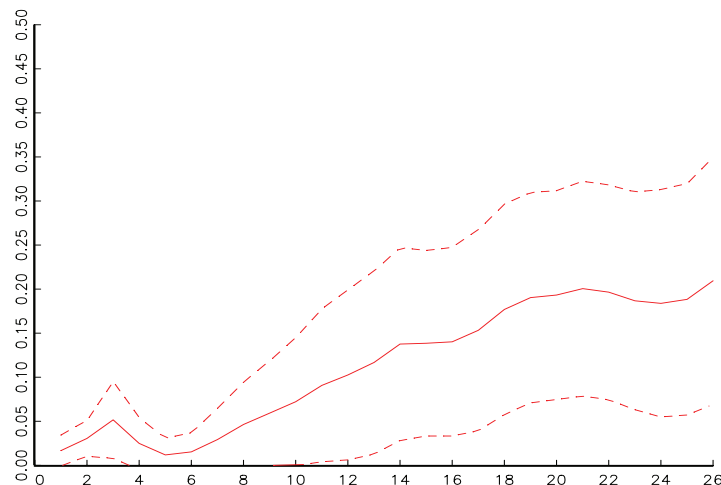

B: German GDP Growth

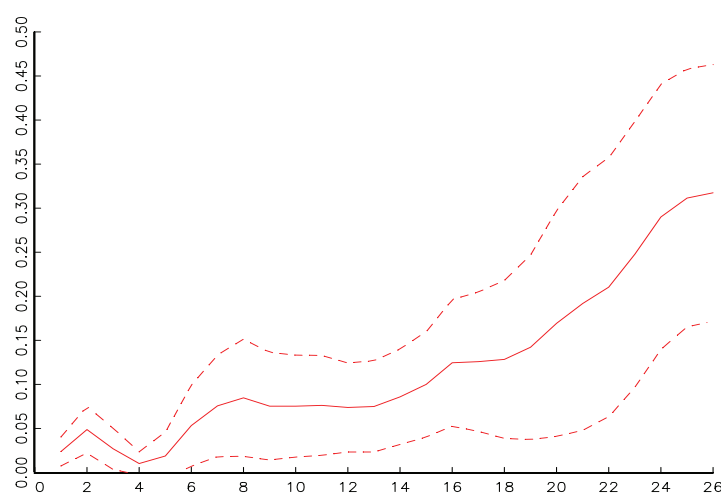

D: German Inflation

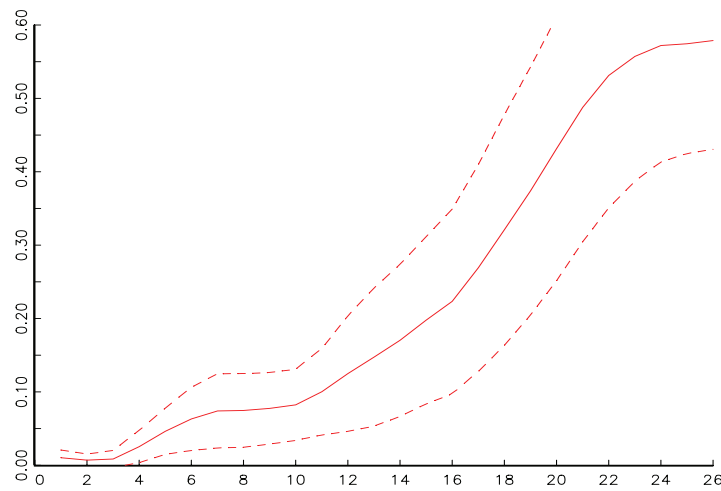

F: German M1 Growth

Figure 3: Estimated Contribution of Order Flows to the Variance of Future GDP growth, Inflation and M1 growth by forecasting horizon, $\tau$, measured in weeks. Dashed lines denote $95 \%$ confidence bands computed as $\pm 1.96 \hat{\sigma}$, where $\hat{\sigma}$ is the standard error of the estimated contribution. Source: Evans and Lyons (2009)

Empirical evidence on the forecasting power of order flow for excess returns was first reported in Evans and Lyons (2007) and Evans and Lyons (2005b). These papers examine the in-sample and out-of-sample forecasting power of six customer order flows in the USD/EUR market received by Citibank between January 1993 and June 1999. Evans and Lyons (2007) find that the withinsample forecasting power of these order flows rises with the forecasting horizon, accounting for $16 \%$ of returns at four weeks. By comparison, the forecasting power of interest differential is in the 2- 
$4 \%$ range. There is, of course, a long tradition in the exchange rate literature of considering out-of sample forecasting performance. Evans and Lyons (2005b) find that out-of sample forecast using the Citibank order flows account for almost $16 \%$ of the sample variance in monthly spot rate changes. Thus, the forecasting power of order flows appears truly significant from an economic perspective.

How do these empirical findings relate to the micro-based model? To address this question, Evans and Lyons (2009) employ a two-step regression procedure. In the first step they regress future macro variables on the order flows. The predicted values from this regression are then used to forecast future excess returns. If the order flows contain information about the future macroeconomic variables used in the first stage, and that information is used by dealers to revise the risk premium embedded in their FX quotes, the coefficients on second stage regression should be significant. This turns out to be the case. Evans and Lyons (2009) find that the order flows convey information about the future growth in M1 and in the M1/GDP ratio for the US and Germany that has forecasting power for the excess return on the USD/EUR. These findings provide a micro-based explanation for the forecasting results discussed above. They indicate that this forecasting power stems from the fact that order flows convey significant information about future macroeconomic conditions, specifically M1 and GDP growth, that dealers use to revise the risk premia they embed in their FX quotes.

\section{Conclusion}

Micro-based research over the past has made some significant progress towards providing exchangerate models with empirically relevant microfoundations, but much remains to be done. Although empirical research examines the role of order flow in exchange-rate determination spans many currencies, trading mechanisms and time periods, to date most theoretical research has focused on understanding the behavior major currency markets with lots of trading activity, such as the USD/EUR and USD/JPY markets. Existing models are less well-suited for studying the behavior of exchange rates between other currencies that trade with much less liquidity. Since the currencies of most counties fall into this category, adapting micro-based models to these markets is an important priority for future research. The models also need to expand their focus beyond the spot markets. Trade in forward contracts, currency swaps and other exchange-rate derivatives account for a large share of FX trading activity, but this portion of the FX market has yet to be studied from a micro-based perspective. This will surely change as data from electronic trading systems becomes more accessible to researchers. 


\section{References}

Berger, D., Chaboud, A., Chernenko, S., Howorka, E., Wright, J., 2008. Order flow and exchange rate dynamics in electronic brokerage system data. Journal of International Economics 75, 93-109.

Bjønnes, G.H., Osler, C.L., Rime, D., 2007. Asymmetric information in the foreign exchange market. typescript, Norges Bank.

Bjønnes, G.H., Rime, D., 2005. Dealer behavior and trading systems in foreign exchange markets. Journal of Financial Economics 75, 571-605.

Bjønnes, G.H., Rime, D., Solheim, H.O.A., 2005. Liquidity provision in the overnight foreign exchange market. Journal of International Money and Finance 24, 177-198.

Boyer, M.M., van Norden, S., 2006. Exchange rates and order flow in the long run. Finance Research Letters 3, 235-243.

Breedon, F., Vitale, P., 2010. An empirical study of portfolio-balance and information effects of order flow on exchange rates. Journal of International Money and Finance 29, $504-524$.

Burnside, C., Eichenbaum, M., Kleshchelski, I., Rebelo, S., 2006. The returns to currency speculation. Working Paper 12489, National Bureau of Economic Research.

Chinn, M., Moore, M., 2009. Private information and the monetary model of exchange rates: Evidence from a novel data set. working paper, Queens University.

Clarida, R., Galı, J., Gertler, M., 1998. Monetary policy rules in practice some international evidence. European Economic Review 42, 1033-1067.

Daníelsson, J., Love, R., 2006. Feedback trading. International Journal of Finance and Economics $11,35-53$.

Engel, C., West, K., 2006. Taylor rules and the deutschmark-dollar real exchange rate. Journal of Money, Credit, and Banking 38, 1175-1194.

Evans, M.D.D., 2002. Fx trading and exchange rate dynamics. Journal of Finance 57, 2405-2447.

Evans, M.D.D., 2010. Order flows and the exchange rate disconnect puzzle. Journal of International Economics 80, $58-71$.

Evans, M.D.D., 2011. Exchange-Rate Dynamics. Princeton Series in International Finance. Princeton University Press. Forthcoming.

Evans, M.D.D., Lyons, R.K., 2002a. Order flow and exchange rate dynamics. Journal of Political Economy 110, 170-180.

Evans, M.D.D., Lyons, R.K., 2002b. Time-varying liquidity in foreign exchange. Journal of Monetary Economics 49, 1025-1051. 
Evans, M.D.D., Lyons, R.K., 2002c. Informational integration and fx trading. Journal of International Money and Finance 21, 807-831.

Evans, M.D.D., Lyons, R.K., 2005a. Do currency markets absorb news quickly? Journal of International Money and Finance 24, 197-217.

Evans, M.D.D., Lyons, R.K., 2005b. Meese-rogoff redux: Micro-based exchange-rate forecasting. American Economic Review Papers and Proceedings 95, 405-414.

Evans, M.D.D., Lyons, R.K., 2007. Exchange rate fundamentals and order flow. Working Paper 13151, National Bureau of Economic Research.

Evans, M.D.D., Lyons, R.K., 2008. How is macro news transmitted to exchange rates? Journal of Financial Economics 88, 26-50.

Evans, M.D.D., Lyons, R.K., 2009. Forecasting exchange rate fundamentals with order flow. Working paper, Georgetown University.

Faust, J., Rogers, J., Wang, S., Wright, J., 2007. The high-frequency response of exchange rates and interest rates to macroeconomic announcements. Journal of Monetary Economics 54, 1051-1068.

Froot, K.A., Ramadorai, T., 2005. Currency returns, intrinsic value, and institutional-investor flows. Journal of Finance 60, 1535-1566.

Gyntelberg, J., Loretan, M., Subhanij, T., Chan, E., 2009. International portfolio rebalancing and exchange rate fluctuations in thailand. Working Paper 287, BIS.

Hasbrouck, J., 1991. Measuring the information content of stock trades. Journal of Finance 46, 179-207.

Killeen, W.P., Lyons, R.K., Moore, M.J., 2006. Fixed versus flexible: Lessons from EMS order flow. Journal of International Money and Finance 25, 551-579.

King, M., Sarno, L., Sojli, E., 2010. Timing exchange rates using order flow: The case of the loonie. Journal of Banking and Finance Forthcoming.

Love, R., Payne, R., 2008. Macroeconomic news, order flows and exchange rates. Journal of Financial and Quantitative Analysis 43, 467-488.

Lyons, R.K., 1997. A simultaneous trade model of the foreign exchange hot potato. Journal of International Economics 42, 275-298.

Mark, N., 2009. Changing monetary policy rules, learning, and real exchange rate dynamics. Journal of Money, Credit and Banking 41, 1047-1070.

Marsh, I.W., O'Rourke, C., 2005. Customer order flow and exchange rate movements: Is there really information content? Working paper, Cass Business School. 
Menkhoff, L., Schmeling, M., 2008. Local information in foreign exchange markets. Journal of International Money and Finance Forthcoming.

Obstfeld, M., Rogoff, K., 2001. The six major puzzles in international macroeconomics: Is there a common cause? NBER Macroeconomics Annual 2000 .

Onur, E., 2008. The role of asymmetric information among investors in the foreign exchange market. International Journal of Finance \& Economics 13, 368-385.

Osler, C.L., 2003. Currency orders and exchange-rate dynamics: Explaining the success of technical analysis. Journal of Finance 58, 1791-1821.

Payne, R., 2003. Informed trade in spot foreign exchange markets: An empirical investigation. Journal of International Economics 61, 307-329.

Rime, D., 2001. Trading in Foreign Exchange Markets. Ph.D dissertation, Norwegian School of Management, Norway.

Rime, D., Sarno, L., Sojli, E., 2010. Exchange rate forecasting, order flow and macroeconomic information. Journal of International Economics 80, $72-88$.

Sager, M., Taylor, M.P., 2008. Commercially available order flow data and exchange rate movements: Caveat emptor. Journal of Money, Credit and Banking 40, 583-625.

Scalia, A., 2008. Is foreign exchange intervention effective? some microanalytical evidence from the czech republic. Journal of International Money and Finance 27, 529-546.

Smyth, N., 2009. Order flow and the exchange rate changes: A look at the NZD/USD and AUD/USD. Discussion Paper 2009/03, Reserve Bank of New Zealand.

Wu, T., 2007. Order flow in the south: Anatomy of the brazilian fx market. typescript, UC Santa Cruz. 


\section{Appendix}

[Overview Table of empirical papers here] 


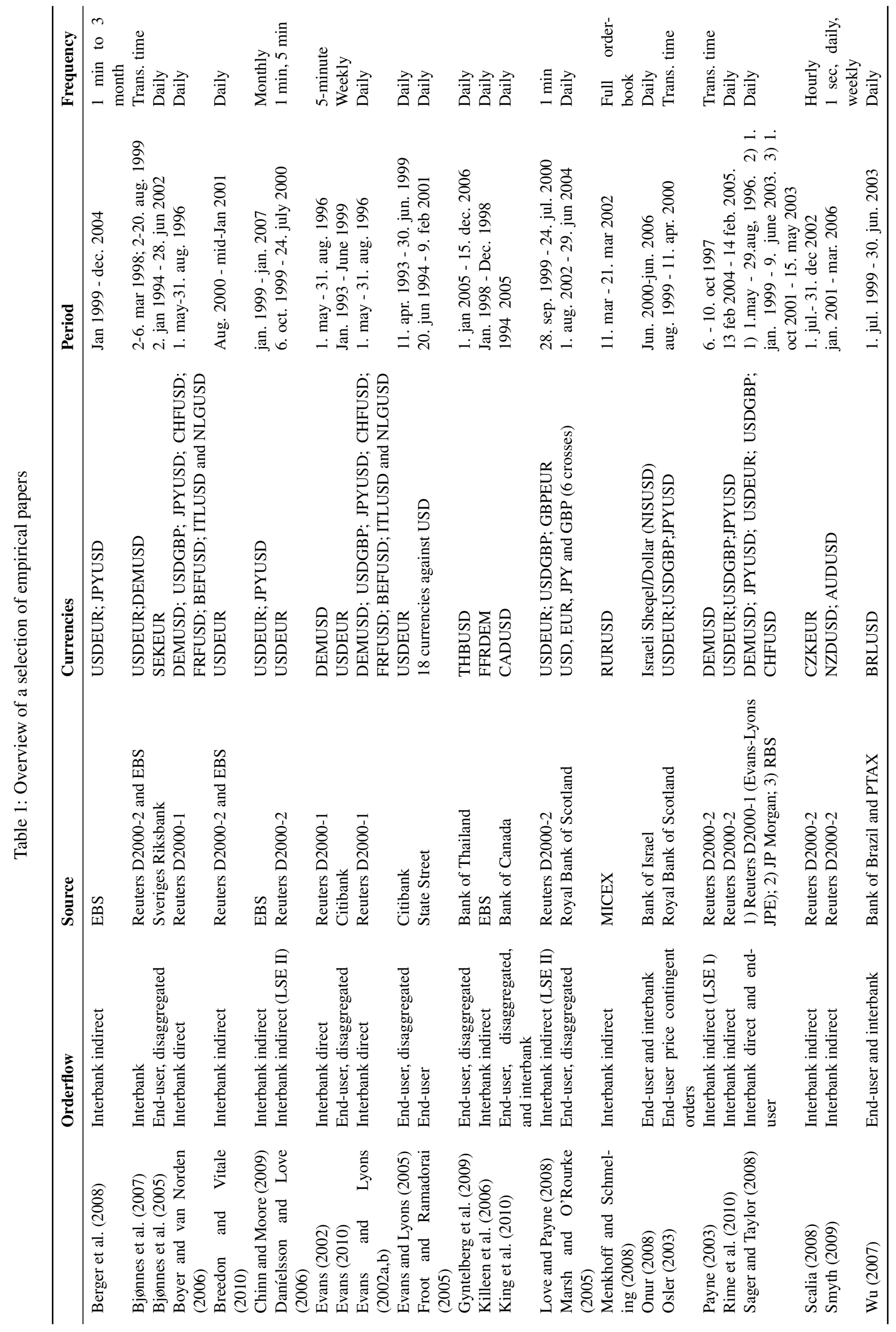

